\title{
The Pricing Strategy of Dual Recycling Channels for Power Batteries of New Energy Vehicles under Government Subsidies
}

\author{
Xiaodong Zhu $\mathbb{D}^{1,2}$ and Wei $\mathrm{Li}^{3}$ \\ ${ }^{1}$ School of Management Engineering, Nanjing University of Information Science and Technology, Nanjing 210044, China \\ ${ }^{2}$ Development Institute of Jiangbei New Area, Nanjing 210044, China \\ ${ }^{3}$ Chang Wang School of Honors, Nanjing University of Information Science and Technology, Nanjing 210044, China
}

Correspondence should be addressed to Xiaodong Zhu; zxd@nuist.edu.cn

Received 9 March 2020; Revised 30 April 2020; Accepted 20 May 2020; Published 13 June 2020

Guest Editor: Lei Xie

Copyright ( 92020 Xiaodong Zhu and Wei Li. This is an open access article distributed under the Creative Commons Attribution License, which permits unrestricted use, distribution, and reproduction in any medium, provided the original work is properly cited.

\begin{abstract}
The vigorous development of the new energy automobile industry has highlighted the issue of efficient recycling of power batteries. Using a Stackelberg game, the pricing mechanism of dual-channel power battery recycling models under different government subsidies is investigated. Consequently, sensitivity analysis and comparison analysis are conducted, providing the pricing decision and the optimal profit of closed-loop supply chain (CLSC) systems. Finally, the effects of recycling efforts, power battery greenness levels, service levels, and consumer green recycling awareness on prices of power batteries and profits are determined through numerical simulations, and the optimal prices under different strategies are compared. The results indicate that recycling prices of each party in the manufacturer subsidy model are relatively high, and consumers' green awareness and the green levels of power batteries are directly proportional to the recycling prices offered by recycling parties. Automobile $4 \mathrm{~S}$ stores and recycling networks should pay attention to the balance between the increase in the cost and the quantity of government subsidies for their recycling efforts. For recycling enterprises, maintaining an appropriate service level can maximize their profits and positively motivate the development of them.
\end{abstract}

\section{Introduction}

In recent years, new-energy automobile industry in China has developed rapidly under the impetus of the government, and the sales of new energy vehicles have soared. With the vigorous development of the new energy vehicle industry, large-scale "retirement" of automotive power batteries has been observed and the subsequent recycling of new energy vehicle power batteries has become a major issue. According to the latest development plan issued by the State Council, the annual output of new energy vehicles will reach 2 million in 2020. It is expected that there will be a "scrap tidal wave," and the quantity of scrapped power batteries will reach between 120,000 and 170,000 tons, resulting in serious environmental and resource problems. Therefore, in order to better perform environmental management and resource utilization, the recycling of used power batteries is not only one of the key links in the new energy vehicle industry, but it can also generate huge economic and environmental benefits. Recycling and avoiding "secondary pollution" have become important concern for enterprises, society, and the country.

However, in the aspect of recycling channels of used power batteries, the system of remanufacturing in China is not complete, and that for used power batteries is rather chaotic. A considerable number of used batteries cannot be collected on a regular basis for professional recycling. Market researches show that some forward-looking remanufacturing enterprises have built their own recycling channels of waste products. Huawei, Lenovo, and other manufacturers have carried out their own recycling channels under the stimulus of production responsibility extension system. They either rely on the recovery of major networks or entrust a third party to recover e-waste and gradually 
form a dual-channel supply chain consisting of recycling networks and traditional retailers. Similarly, the dualchannel supply chain has also been put into practice in the field of recycling used power batteries as well. Many regions in China have started to build and share power battery recycling networks or cooperate with $4 \mathrm{~S}$ stores in order to form a dual-channel supply chain and explore the marketoriented pricing mechanism of used power batteries. In practice, however, recycling channels face multiple obstacles. On the one hand, there is a competitive relationship between recycling channels, and the recycling efforts of $4 \mathrm{~S}$ stores and recycling networks affect the decision-making behavior of each party and the pricing strategy of the dualchannel supply chain. On the other hand, there is always a difference in service level between $4 \mathrm{~S}$ stores and recycling networks, and the difference in greenness level of different power batteries poses a challenge to the pricing strategy of manufacturers. Based on the practical background, it can be seen that the research on the recycling pricing strategy of used power batteries in dual-channel supply chains is not only of theoretical significance but also of practical guiding significance.

In recent years, new-energy automobile industry has developed rapidly under government subsidies. However, the state's "transfusion-type" support for the development of the new energy industry has led to frequent occurrences of new energy vehicles "scams." According to the Public Notice on The 2017 New Energy Vehicle Promotion and Application of Subsidy Funds Liquidation Audit Final Situation issued by the Ministry of Industry and Information Technology on October 11, 2019, the subsidy audit standards of new energy vehicles are getting stricter year by year, which reflects that China is gradually tightening the supervision of the new energy vehicle industry. With the gradual decline of new energy vehicles' subsidies, China's new energy vehicle market has gradually shifted from being policy-oriented to market-oriented. Given this policy background and the high level of battery scrapping, the market space for power battery recycling is very huge. However, the government's subsidies are limited, so it is worth considering which recycling subject the government chooses to subsidize. Additionally, it is important to study how to motivate the main parties of the supply chain to maximize recycling efforts and improve consumers' green recycling awareness, as these have become urgent problems for power battery recycling. The existing recycling methods of used power batteries are mainly divided into two channels: automobile $4 \mathrm{~S}$ stores and recycling networks.

Aligning with the abovementioned policy guidance and background and considering the impact of government subsidies, this paper builds a dual-channel power battery recycling model under a Stackelberg game. Recycling efforts, power battery greenness levels, service levels, and consumer green recycling awareness are introduced. The optimal price structures of each subject under different models and the effects of each factor on recycling prices were analyzed through numerical simulations, and the optimal prices under different strategies were compared. Finally, relevant countermeasures and suggestions for power battery recycling are proposed based on the research results. The purpose of this article is to answer the following questions: (1) under the circumstance of different government subsidies, how do each recycling party in the supply chain carry out pricing strategies of used power batteries? (2) In a situation in which government subsidies are becoming tighter, how do government departments choose the subsidy recipient and determine the quantity of subsidy needed in order to maximize the incentive for recycling power batteries and encourage the sustainable development of new energy companies? (3) In the case that there are differences in recycling efforts and service levels between recycling channels, how do each party in the power battery recycling supply chain formulate pricing strategies to improve its own competitive advantages and benefits?

The remainder of this article is organized as follows: Section 2 reviews the literature on new energy vehicles, closed-loop supply chain (CLSC) pricing, and government subsidies; Section 3 contains the problem description and model assumptions; Section 4 introduces the construction and solution of the dual-channel CLSC model under five strategies; the Stackelberg game is used to solve the pricing and profitability problems in the models; Section 5 presents the comparison and sensitivity analyses through numerical simulations to demonstrate the application of the model; and finally, Section 6 presents the conclusions.

\section{Literature Review}

The literature related to this article mainly focuses on three aspects: power battery recycling of new energy vehicles, CLSC pricing, and government subsidies.

The power battery contains a large quantity of precious metal resources, which are likened to "urban minerals." Recycling nickel, cobalt, and rare metals in power batteries can generate enormous economic benefits for enterprises, effectively reducing the environmental pollution risk of power batteries and alleviating the dependence of rare precious metals on foreign resources in China. In terms of power battery recycling for new energy vehicles, Alamerew and Brissaud [1] used a system dynamics approach to study costs, revenues, strategies, and regulatory decisions. Taking electric vehicle batteries as an example, the authors discussed the main pillars of circular economy research. Zhu et al. [2] studied the optimal channel selection and battery capacity allocation strategy of electric vehicle manufacturers with regard to battery recycling. The study found that the optimal channel selection of each electric vehicle manufacturer depends on the procurement cost from external battery suppliers. Li et al. [3] studied the impact of subsidy policies and dual credit policies on the production decisions of new energy vehicles and fuel vehicles, considering battery recycling in a competitive environment. The problem of joint recycling and coordination between upstream and downstream operations of the power battery three-level CLSC was studied. Harper et al. [4] proposed that lithiumion battery recycling by electric vehicles can provide valuable sources of secondary materials. They also summarized and evaluated the current methods of recycling and reusing 
lithium-ion batteries for electric vehicles, emphasizing the future development direction. Betancourt-Torcat et al. [5] proposed an optimization decision-making method for the main energy sources and power generation, providing recommendations for the electric vehicle power battery power supply chain. Tang et al. [6] considered the application of the reward and punishment mechanism in the battery recycling of scrapped electric vehicles and established a Stackelberg game theory model to study the social, economic, and environmental impact of recycling used electric vehicle batteries.

CLSCs, which follow the theory of a circular economy with the goal of maximizing the product life cycle, is one of the effective ways to develop the remanufacturing industry. In terms of CLSC pricing, He et al. [7] explored the channel structure and pricing decisions of manufacturers through a two-channel CLSC model and studied government's subsidy policies for competing new and remanufactured products. Taleizadeh et al. [8] considered the social and environmental aspects of supply chain decision-making and proposed a tactical decision-making model that included product price and logistics decisions. Kabul and Parlaktürk [9] considered a decentralized supply chain consisting of a retailer and a supplier. The supplier provided services to forward-looking consumers in two periods and set prices from the perspective of the retailer and supplier, respectively. Chen and Ho [10] explored whether supplier sales rely on supplier participation in environmental protection practices (PEPs), and, if so, how is this relationship regulated by the customer's PEP level? Zhang and Xiong [11] considered the design of two optimal pricing contracts for retailers when the information of manufacturer's recycling cost was asymmetric. Pi et al. [12] studied pricing and service strategies under the competition and cooperation of retailers in a dual-channel supply chain system composed of one manufacturer and two retailers. Under the circumstance of revenue sharing in the forward supply chain and channel cost sharing in the reverse supply chain, Jiaping et al. [13] discussed how the product pricing and service optimization decisions can be made. Xie [14] et al. studied the contract coordination of centralized and decentralized dual-channel CLSC in the context of online/offline dual channels. Chao et al. [15] proposed a risk decentralized contract model with a loss-sharing mechanism and unilateral compensation mechanism to manage procurement inventory risk in order to stimulate retailers to expand product orders. Researches on the above two aspects mostly focus on the competition and coordination of recycling channels, manufacturers' monopoly decisions, and consumer preferences, while the literature on the impact of government subsidies on pricing strategies of recycling power batteries is relatively scarce. In this study, we mainly focus on the CLSC's reverse channel. The pricing strategy and profitability of each entity were studied through a dual-channel supply chain model.

In terms of government subsidies, Wang et al. [16] studied the allocation strategy of government subsidies under an e-waste reverse supply chain consisting of a recycler, a remanufacturer, and two retailers. The optimal pricing decision of multisubsidized government subsidies and their effects are studied. Mitra and Webster [17] studied the effect of government subsidies to promote remanufacturing activities and considered three cases in which the government gave subsidies to manufacturers alone, remanufacturers alone, or both. Calcott and Walls [18] explored the impact of government subsidies on recycling rates in the case of manufacturer recycling. Pfeifer and Ovchinnikov [19] distinguished between customer life cycle value and consumer willingness and studied the impact of government subsidies on product demand. Guo et al. [20] considered the optimal recycling and production strategy of a CLSC in the case of supply interruption and government subsidies and provided a reference for the operation of enterprises with supply interruptions and the design of a reasonable government subsidy mechanism. Zhao and Sun [21] established two profit distribution models for CLSCs without government subsidies and with government subsidies and compared the profit distribution of members of the two models. Wan and Hong [22] established a Stackelberg game model to analyze the optimal pricing and recycling policies of a CLSC and discussed the effects of subsidy policies. Nielsen et al. [23] studied the impact of government subsidy policies on optimal pricing and investment decisions in order to improve product quality and recycling under the goal of social welfare optimization. However, among the literature on government subsidies, there are few researches related to the recycling of power batteries. This paper introduces the government subsidy and studies the pricing mechanism under different subsidy strategies. Then, we investigated and compared the pricing strategies and profits under different models, providing management suggestions for recycling enterprises in the supply chain.

Based on the above, we can conclude that there are limited researches on power battery recycling and related government regulations. From the perspective of the supply chain, the actual situation of pricing strategies and the profitability of all parties need further study. This study is different from previous research in three ways. First, this paper not only considers traditional recycling methods of power batteries, which in this paper is automobile $4 \mathrm{~S}$ stores, but also considers the current emerging recycling method, namely, recycling networks. Consequently, a dual-channel supply chain for recycling power batteries was built based on the actual situation. Second, this study uses the Stackelberg game to study the optimal pricing strategy and its influencing factors for the main players in a supply chain led by the remanufacturer. Pricing decisions and comparative analysis under different government subsidy strategies are performed as well. Third, this paper regards the greenness level of remanufactured batteries and consumers' green recycling awareness under the government regulations; then, we introduce the recycling effort and service level for sensitivity simulation analysis and propose countermeasures and recommendations for new energy power battery recycling.

\section{Problem Description and Assumptions}

This study builds a two-stage CLSC consisting of a manufacturer, a new energy vehicle $4 \mathrm{~S}$ store, and a recycling network, as shown in Figure 1. We assume that the supply 


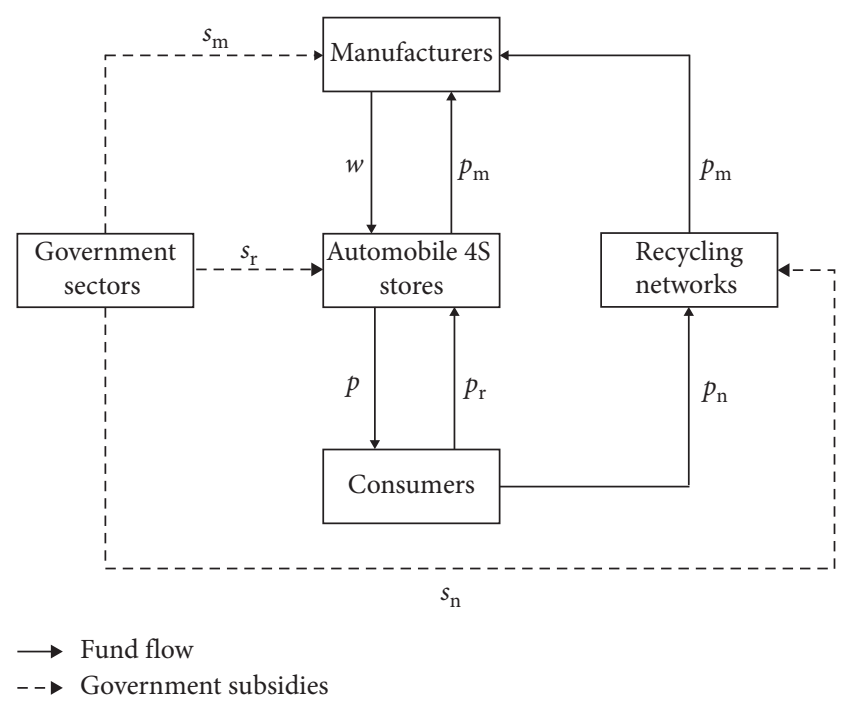

Figure 1: Flow chart of power battery recycling of new energy vehicles.

capacity of the market is strong enough, and new energy automobile companies can meet the purchasing demand of consumers. The market supply and demand are balanced. In the sales link, manufacturers sell power batteries to automobile $4 \mathrm{~S}$ stores at the wholesale price $\omega$, and $4 S$ stores sell power batteries to consumers at price $p$. New power batteries reach consumers through the forward supply chain. In order to characterize the relationship between the sales price of power batteries and demand, according to the analysis of Savaskan [3], it is assumed that the market demand function for remanufactured products is $q=\alpha-\beta p$, where $\alpha, \beta>0$ and are both constant. In the recycling link, $4 \mathrm{~S}$ stores recycle used power batteries from consumers at the price $p_{\mathrm{r}}$, while recycling networks recycle used power batteries from consumers at the price $p_{\mathrm{n}}$. Finally, the manufacturers recycle all used power batteries from $4 S$ stores and recycling networks at the price $p_{\mathrm{m}}$. The recycling power batteries are returned to the manufacturers through the reverse supply chain. To ensure the profit of each entity, $p_{\mathrm{m}}>p_{\mathrm{n}}, p_{\mathrm{m}}>p_{\mathrm{r}}$, and $\omega>p$ must be met. $C_{\mathrm{m}}$ is the unit cost of the new power battery, and $C_{\mathrm{r}}$ is the unit cost of the remanufactured power battery, so $C_{\mathrm{r}}<C_{\mathrm{m}}$ must exist. The difference between the two is given by $\triangle=C_{\mathrm{m}}-C_{\mathrm{r}}$, which represents the cost saved by remanufacturing.

According to the industry background of power battery recycling, this paper considers the influence of consumers' awareness of green recycling, greenness level of power batteries, recycling efforts, and service level of recycling outlets and $4 \mathrm{~S}$ stores on the pricing strategy of recycling used power battery. It is assumed that consumers have the same willingness to buy new power batteries and remanufactured power batteries on the market, and the two products have the same market price. In the recycling link, the recycling quantity of used power batteries of $4 \mathrm{~S}$ stores and recycling networks are $q_{\mathrm{r}}=\theta S-b_{2} p_{\mathrm{n}}+$ $b_{1} p_{\mathrm{r}}+\rho\left(v_{\mathrm{r}}-v_{\mathrm{n}}\right)+k g_{\mathrm{m}}$ and $q_{\mathrm{n}}=(1-\theta) S-b_{2} p_{\mathrm{r}}+b_{1} p_{\mathrm{n}}+$ $\rho\left(v_{\mathrm{n}}-v_{\mathrm{r}}\right)$, where $S$ is the total market demand, $\theta$ is the market share of the consumer demand of $4 \mathrm{~S}$ stores in the dual-channel supply chain, $b_{1}$ is the consumers' sensitivity coefficient to the recycling price, and $b_{2}$ is the channel competition coefficient between $4 \mathrm{~S}$ stores and recycling networks. In order to ensure a good competitive environment and positive profits for the recycling parties, we assume $b_{1}>b_{2}>0 . k$ and $g_{\mathrm{m}}$, respectively, represent consumers' awareness of green recycling and the greenness level of power batteries. When either factor improves, consumers are more willing to choose regular channels to recycle used power batteries and more willing to buy remanufactured power batteries, and the recycling quantity of power batteries of $4 \mathrm{~S}$ stores and recycling networks will increase. Since the dualchannel recycling supply chain is considered in this paper, service level is an important factor to be considered among competitive channels. $v_{\mathrm{r}}$ and $v_{\mathrm{n}}$ represent the service levels provided by $4 \mathrm{~S}$ stores and recycling networks to consumers, respectively. The costs spent in service levels are recorded as $v_{\mathrm{r}}^{2}$ and $v_{\mathrm{n}}^{2}$ [24]. $\rho$ represents the transfer coefficient of market demand to service level differences.

In addition, this paper also considers the influence of the recycling efforts of $4 \mathrm{~S}$ stores and recycling networks on the pricing and profit of the supply chain. In the process of recycling power batteries from consumers, the degree at which $4 \mathrm{~S}$ stores and recycling networks respond to the national call for publicity and recycling efforts is set at $e_{\mathrm{r}}$ and $e_{\mathrm{n}}$, respectively, and the government, according to their respective efforts, provides $e_{\mathrm{r}} s_{\mathrm{r}}$ and $e_{\mathrm{n}} s_{\mathrm{n}}$ subsidies, respectively. Since manufacturers are involved in the recycling and disassembly of power batteries, the greenness of power batteries is set to $g_{\mathrm{m}}$. Assuming that the greenness level of batteries produced by manufacturers meets subsidy requirements, the government examines per-unit products based on the greenness of their remanufactured products. $C_{\mathrm{r}} t\left(g_{\mathrm{m}}-g\right)$ is the quantity of government subsidy, where $t$ is the unit adjustment coefficient of subsidy, $t \leq 1$.

Specific notations are shown in Table 1. The superscripts "ND" and "NC" in the variables represent the decentralized and centralized decision-making models without government subsidies, respectively. In the optimal decision results, the subscripts " $m$," " $r$," and " $n$ " represent the three main parties, the manufacturers, automobile $4 \mathrm{~S}$ stores, and recycling networks, respectively.

\section{Construction and Solution of the Dual- Channel CLSC Model under Different Strategies}

Based on the operating framework of the dual-channel power battery recycling CLSC, the pricing strategies under centralized and decentralized supply chain decision-making are studied separately below. Under the decentralized decision-making model, the main parties of the supply chain aim to maximize their own profits. Under centralized decision-making, the main players of the supply chain aim to maximize the overall profit of the supply chain. The decentralized and centralized supply chain decision-makings are modelled and solved.

4.1. Decentralized Decision Model without Government Subsidy (Model ND). Under the decentralized decisionmaking model without government subsidies (denoted as 
TABle 1: Notations.

\begin{tabular}{|c|c|}
\hline Notation & Definition \\
\hline \multicolumn{2}{|c|}{ Automobile $4 S$ stores } \\
\hline$p$ & Unit price of one new power battery \\
\hline$q$ & Consumers' demand for power batteries \\
\hline$q_{\mathrm{r}}$ & Recycling quantity of used power batteries in $4 \mathrm{~S}$ stores \\
\hline$p_{\mathrm{r}}$ & The price that $4 \mathrm{~S}$ stores pay consumers for recycling power batteries \\
\hline$v_{\mathrm{r}}$ & Service level provided by $4 \mathrm{~S}$ stores to consumers \\
\hline$e_{\mathrm{r}}$ & The publicity and recycling efforts of $4 \mathrm{~S}$ stores \\
\hline$\mu_{\mathrm{r}}$ & $4 \mathrm{~S}$ stores' recycling effort effect coefficient \\
\hline \multicolumn{2}{|c|}{ Manufacturers } \\
\hline$C_{\mathrm{m}}$ & Cost of new power batteries \\
\hline$C_{\mathrm{r}}$ & Cost of remanufacturing power batteries \\
\hline$\omega$ & Wholesale price for power batteries \\
\hline$p_{\mathrm{m}}$ & The price of recycling used power batteries that manufacturers pay $4 \mathrm{~S}$ stores and recycling networks \\
\hline$g_{\mathrm{m}}$ & Greenness level of remanufactured power battery \\
\hline \multicolumn{2}{|c|}{ Recycling networks } \\
\hline$p_{\mathrm{n}}$ & The price that recycling networks pay consumers to recycle power batteries \\
\hline$e_{\mathrm{n}}$ & The publicity and recycling efforts of recycling networks \\
\hline$\mu_{\mathrm{n}}$ & Recycling networks' recycling effort coefficient \\
\hline \multicolumn{2}{|l|}{ Consumer } \\
\hline$k$ & Consumers' awareness of green recycling \\
\hline$S$ & Total market demand for recycling power batteries \\
\hline$\theta$ & Market share of consumers' demand for recycling power batteries in the distribution channel of $4 \mathrm{~S}$ stores \\
\hline$b_{1}$ & Consumers' sensitivity to recycling prices \\
\hline$b_{2}$ & Channel competition coefficient between $4 \mathrm{~S}$ stores and recycling networks \\
\hline$\rho$ & The transfer coefficient of consumer demand to the difference in service level \\
\hline \multicolumn{2}{|c|}{ Government } \\
\hline$s_{\mathrm{r}}$ & The unit subsidy provided by the government to $4 \mathrm{~S}$ stores \\
\hline$s_{\mathrm{m}}$ & The unit subsidy provided by the government to manufacturers \\
\hline$s_{\mathrm{n}}$ & The unit subsidy provided by the government to recycling networks \\
\hline$g$ & The minimum green level required for government subsidies \\
\hline$t$ & Government unit subsidy adjustment factor \\
\hline$r$ & Government unit subsidy coefficient \\
\hline
\end{tabular}

“model ND"), manufacturers, 4S stores, and recycling networks each pursue their own profit maximization. The manufacturers, $4 \mathrm{~S}$ stores, and recycling networks play a Stackelberg game in which the manufacturers are the leader, and the $4 \mathrm{~S}$ stores and the recycling networks are the followers. The order of decision is as follows: the manufacturers first decide the wholesale price $\omega$ and the recycling price $p_{\mathrm{m}}$, and then, the $4 \mathrm{~S}$ stores and the recycling networks decide the sales price $p$ and the recycling prices $p_{\mathrm{r}}$ and $p_{\mathrm{n}}$. At this point, the profit functions of manufacturers, $4 \mathrm{~S}$ stores, and recycling networks are as follows:

$$
\begin{aligned}
& \pi_{\mathrm{m}}^{\mathrm{ND}}\left(\omega, p_{\mathrm{m}}\right)=\left(\omega-C_{\mathrm{m}}\right) q+\left(C_{\mathrm{m}}-C_{\mathrm{r}}\right)\left(q_{\mathrm{r}}+q_{\mathrm{n}}\right)-p_{\mathrm{m}}\left(q_{\mathrm{r}}+q_{\mathrm{n}}\right) \\
& \pi_{\mathrm{r}}^{\mathrm{ND}}\left(p_{\mathrm{r}}, p\right)=(p-\omega) q+\left(p_{\mathrm{m}}-p_{\mathrm{r}}\right) q_{\mathrm{r}}-v_{\mathrm{r}}^{2}, \\
& \pi_{\mathrm{n}}^{\mathrm{ND}}\left(p_{\mathrm{n}}\right)=\left(p_{\mathrm{m}}-p_{\mathrm{n}}\right) q_{\mathrm{n}}-v_{\mathrm{n}}^{2} .
\end{aligned}
$$

Theorem 1. In model ND, the optimal prices for new and remanufactured products can be calculated as follows: 


$$
\begin{aligned}
& \omega^{\mathrm{ND} *}=\frac{\alpha+\beta C_{\mathrm{m}}}{2 \beta}, \\
& p^{\mathrm{ND} *}=\frac{3 \alpha+\beta C_{\mathrm{m}}}{4 \beta}, \\
& p_{\mathrm{n}}^{\mathrm{ND} *}=\frac{B+b_{1}^{2} b_{2}\left(11 S-2 b_{2} \Delta+10 k g_{\mathrm{m}}+12 A\right)-2 b_{1}^{3}\left(-3 S-b_{2} \Delta-2 k g_{\mathrm{m}}-4 A\right)+b_{1} b_{2}^{2}\left(-S+2 k g_{\mathrm{m}}-4 A\right)}{4 b_{1}\left(b_{1}-b_{2}\right)\left(4 b_{1}^{2}-b_{2}^{2}\right)} \\
& p_{\mathrm{r}}^{\mathrm{ND} *}=\frac{B+b_{1} b_{2}^{2}\left(3 S+2 k g_{\mathrm{m}}+4 A\right)+2 b_{1}^{3}\left(-S+b_{2} \Delta+2 k g_{\mathrm{m}}-4 A\right)+b_{1}^{2} b_{2}\left(-S-2 b_{2} \Delta+10 k g_{\mathrm{m}}-12 A\right)}{4 b_{1}\left(b_{1}-b_{2}\right)\left(4 b_{1}^{2}-b_{2}^{2}\right)} \\
& p_{\mathrm{m}}^{\mathrm{ND} *}=\frac{2 b_{1}^{3}\left(C_{\mathrm{m}}-C_{\mathrm{r}}\right)+b_{1} b_{2}\left(S+2 k g_{\mathrm{m}}\right)-b_{2}^{2}\left(S+2 k g_{\mathrm{m}}\right)+b_{1}^{2}\left(S-2 b_{2}\left(C_{\mathrm{m}}-C_{\mathrm{r}}\right)+2 k g_{\mathrm{m}}\right)}{4 b_{1}^{2}\left(b_{1}-b_{2}\right)} .
\end{aligned}
$$

By substituting the above optimal solution into the corresponding profit function, the optimal profits of the manufacturers, $4 \mathrm{~S}$ stores, and recycling networks under the model ND are $\pi_{\mathrm{m}}^{N D *}, \pi_{\mathrm{r}}^{N D *}$, and $\pi_{\mathrm{n}}^{N D *}$. To simplify the results, let $\rho v_{\mathrm{n}}-\rho v_{\mathrm{r}}-S \theta=A$ and $4 b_{1}^{4}\left(C_{\mathrm{m}}-C_{\mathrm{r}}\right)-b_{2}^{3}\left(S+2 k g_{\mathrm{m}}\right)=B$. Note that the proof of all theorems can be found in Appendix $A$, and the proof of all propositions can be found in Appendix B.

Proposition 1. As the consumers' sensitivity coefficient of recycling prices increases, the number of used power batteries recycled by $4 S$ stores and recycling networks both increases.

Proposition 1 shows that the increase in the sensitivity of the recycling price has a positive feedback effect on the quantity of recycling and the profit of the supply chain. There are several reasons contributing to this conclusion. When consumers pay more attention to the recycling price level, $4 \mathrm{~S}$ stores and recycling networks are prompted to increase recycling prices. Consequently, the recycling willingness of consumers increase and so do the recycling quantity of used power batteries.

$$
\begin{aligned}
& p^{\mathrm{NC} *}=\frac{\alpha+\beta C_{\mathrm{m}}}{2 \beta}, \\
& p_{\mathrm{r}}^{\mathrm{NC} *}=-\frac{b_{1}^{2}\left(-C_{\mathrm{m}}+C_{\mathrm{r}}\right)+b_{2}\left(S-S \theta+b_{2}\left(C_{\mathrm{m}}-C_{\mathrm{r}}\right)+k g_{\mathrm{m}}+\rho v_{\mathrm{n}}-\rho v_{\mathrm{r}}\right)+b_{1}\left(S \theta+k g_{\mathrm{m}}-\rho v_{\mathrm{n}}+\rho v_{\mathrm{r}}\right)}{2\left(b_{1}^{2}-b_{2}^{2}\right)} \\
& p_{\mathrm{n}}^{\mathrm{NC} *}=\frac{b_{1}^{2}\left(C_{\mathrm{m}}-C_{\mathrm{r}}\right)+b_{1}\left(-S+S \theta-k g_{\mathrm{m}}-\rho v_{\mathrm{n}}+\rho v_{\mathrm{r}}\right)-b_{2}\left(S \theta+b_{2}\left(C_{\mathrm{m}}-C_{\mathrm{r}}\right)+k g_{\mathrm{m}}-\rho v_{\mathrm{n}}+\rho v_{\mathrm{r}}\right)}{2\left(b_{1}^{2}-b_{2}^{2}\right)}
\end{aligned}
$$

The overall optimal profit $\pi^{N C *}$ of the CLSC under the model NC can be obtained by substituting the above optimal solutions in equation (5).

Proposition 3. Whether under decentralized or centralized decision-making, when the service level difference $v_{n}-v_{r}$ increases, $p_{n}$ decreases, and $p_{r}$ increases.
Proposition 2. The higher the consumers' awareness of green recycling $k$, the higher the recycling prices $p_{r}$ and $p_{n}$ paid by $4 S$ stores and recycling networks to consumers, respectively.

Proposition 2 shows that increased consumer awareness of green recycling will directly increase the quantity of recycled power batteries, the recycling prices, and consumers' demand for remanufactured products, stimulating manufacturers to produce power batteries. The broad market demand will also bring a higher profit space to the main players in the supply chain.

4.2. Centralized Decision Model without Government Subsidies (Model NC). Under centralized decision-making, manufacturers, $4 \mathrm{~S}$ stores, and recycling networks are jointly pursuing the overall maximum profit of the CLSC. At this time, the total profit model is

$$
\begin{aligned}
\pi^{\mathrm{NC}}\left(p, p_{\mathrm{r}}, p_{\mathrm{n}}\right)= & \left(p-C_{\mathrm{m}}\right) q+\left(C_{\mathrm{m}}-C_{\mathrm{r}}\right)\left(q_{\mathrm{r}}+q_{\mathrm{n}}\right) \\
& -p_{\mathrm{r}} q_{\mathrm{r}}-p_{\mathrm{n}} q_{\mathrm{n}}-v_{\mathrm{r}}^{2}-v_{\mathrm{n}}^{2} .
\end{aligned}
$$

Theorem 2. The optimal prices of model NC are as follows: 
batteries. Therefore, the increase in service level differences has opposing effects on the recycling prices of $4 \mathrm{~S}$ stores and those of recycling networks.

4.3. Manufacturer Subsidy Strategy (Model M). This study investigates the actual background of new energy vehicle subsidies and related regulations. We found that government subsidies provided to manufacturers are closely related to the greenness levels of remanufactured power batteries produced by them. The Notice on Promoting the Application of Financial Subsidy Policies for New Energy Vehicles clearly stipulates that the fuel saving rate of plug-in hybrid electric vehicles (including extended range) must be greater than $60 \%$. The subsidy adjustment factor for $60 \%$ to $65 \%$ fuel efficiency is 0.8 , while the subsidy adjustment factor for more than $70 \%$ fuel efficiency is 1 . Therefore, this study sets the government unit subsidy coefficient as $r=t\left(g_{\mathrm{m}}-g\right)$, where $t$ is the unit subsidy adjustment coefficient factor, $t \leq 1, r \geq 0$. Therefore, the unit remanufactured power battery subsidy quantity is $C_{\mathrm{r}} t\left(g_{\mathrm{m}}-g\right)$. At this time, the profit functions of the manufacturers, the $4 \mathrm{~S}$ stores, and the recycling networks are

$$
\begin{aligned}
\pi_{\mathrm{m}}^{\mathrm{M}}\left(\omega, p_{\mathrm{m}}, t\right)= & \left(\omega-C_{\mathrm{m}}\right) q+\left(C_{\mathrm{m}}-C_{\mathrm{r}}-p_{\mathrm{m}}\right)\left(q_{\mathrm{r}}+q_{\mathrm{n}}\right) \\
& +C_{\mathrm{r}} t\left(g_{\mathrm{m}}-g\right)\left(q_{\mathrm{r}}+q_{\mathrm{n}}\right) \\
\pi_{\mathrm{r}}^{\mathrm{M}}\left(p_{\mathrm{r}}, p\right)= & (p-\omega) q+\left(p_{\mathrm{m}}-p_{\mathrm{r}}\right) q_{\mathrm{r}}-v_{\mathrm{r}}^{2} \\
\pi_{\mathrm{n}}^{\mathrm{M}}\left(p_{\mathrm{n}}\right)= & \left(p_{\mathrm{m}}-p_{\mathrm{n}}\right) q_{\mathrm{n}}-v_{\mathrm{n}}^{2}
\end{aligned}
$$

Theorem 3. The optimal solutions of model $M$ are as follows:

$$
\begin{aligned}
& p^{M *}=\frac{3 \alpha+\beta C_{\mathrm{m}}}{4 \beta}, \\
& \omega^{M *}=\frac{\alpha+\beta C_{\mathrm{m}}}{2 \beta}, \\
& p_{\mathrm{m}}^{M *}=\frac{-S b_{1}^{2}-S b_{1} b_{2}+S b_{2}^{2}-2 k b_{1}^{2} g_{\mathrm{m}}-2 k b_{1} b_{2} g_{\mathrm{m}}+2 k b_{2}^{2} g_{\mathrm{m}}}{2 b_{1}^{2}\left(b_{2}-b_{1}\right)} \\
& t_{\mathrm{m}}^{M *}=\frac{S b_{1}^{2}+S b_{1} b_{2}-S b_{2}^{2}-2 b_{1}^{3} C_{\mathrm{m}}+2 b_{1}^{2} b_{2} C_{\mathrm{m}}+2 b_{1}^{3} C_{\mathrm{r}}-2 b_{1}^{2} b_{2} C_{\mathrm{r}}+2 k b_{1}^{2} g_{\mathrm{m}}+2 k b_{1} b_{2} g_{\mathrm{m}}-2 k b_{2}^{2} g_{\mathrm{m}}}{2 b_{1}^{2}\left(b_{2}-b_{1}\right) C_{\mathrm{r}}\left(g-g_{\mathrm{m}}\right)} \\
& p_{\mathrm{n}}^{M *}=\frac{b_{2}^{2}\left(S+2 k g_{\mathrm{m}}\right)+b_{1} b_{2}\left(3 S-2 S \theta+4 k g_{\mathrm{m}}+2 \rho v_{\mathrm{n}}-2 \rho v_{\mathrm{r}}\right)+b_{1}^{2}\left(-S+2 S \theta-2 \rho v_{\mathrm{n}}+2 \rho v_{\mathrm{r}}\right)}{2 b_{1}\left(b_{1}-b_{2}\right)\left(2 b_{1}+b_{2}\right)} \\
& p_{\mathrm{r}}^{M *}=\frac{b_{2}^{2}\left(S+2 k g_{\mathrm{m}}\right)+b_{1}^{2}\left(S-2 S \theta+2 \rho v_{\mathrm{n}}-2 \rho v_{\mathrm{r}}\right)+b_{1} b_{2}\left(S+2 S \theta+4 k g_{\mathrm{m}}-2 \rho v_{\mathrm{n}}+2 \rho v_{\mathrm{r}}\right)}{2 b_{1}\left(b_{1}-b_{2}\right)\left(2 b_{1}+b_{2}\right)} .
\end{aligned}
$$

By substituting the above optimal solution into the corresponding profit function, the optimal profits of the manufacturers, $4 \mathrm{~S}$ stores, and recycling networks under model $\mathrm{M}$ are $\pi_{\mathrm{m}}^{M *}, \pi_{\mathrm{r}}^{M *}$, and $\pi_{\mathrm{n}}^{M *}$.

Proposition 4. When the greenness level $g_{m}$ of power batteries produced by manufacturers increases, the unit subsidy adjustment coefficient factor $t$ increases. Accordingly, the government unit subsidy coefficient $r$ and the government unit subsidy quantity also increase.

Proposition 4 shows that when the greenness level of power batteries increases, the government increases the unit subsidy adjustment factor for manufacturers accordingly, encouraging manufacturers to pay attention to the greenness level of power batteries in future production. Therefore, promoting the greenness level of power batteries increases consumers' purchasing demand for power batteries, enhancing the environmental protection of the CLSC and society.

4.4. Automobile $4 S$ Stores Subsidy Strategy (Model R). In response to the national call on the recycling of power batteries of new energy vehicles, $4 \mathrm{~S}$ stores encourage consumers to recycle used power batteries by using publicity or feedback surveys. Therefore, the recycling quantities of $4 \mathrm{~S}$ stores and recycling networks are $q_{\mathrm{r}}^{\mathrm{R}}=\theta S-b_{2} p_{\mathrm{n}}+b_{1} p_{\mathrm{r}}+$ $\rho\left(v_{\mathrm{r}}-v_{\mathrm{n}}\right)+k g_{\mathrm{m}}+\mu_{\mathrm{r}} e_{\mathrm{r}} \quad$ and $\quad q_{\mathrm{n}}^{\mathrm{R}}=(1-\theta) S-b_{2} p_{\mathrm{r}}+$ $b_{1} p_{\mathrm{n}}+\rho\left(v_{\mathrm{n}}-v_{\mathrm{r}}\right)+k g_{\mathrm{m}}-\mu_{\mathrm{r}} e_{\mathrm{r}}$. Here, $e_{\mathrm{r}}$ stands for the recycling effort of the $4 \mathrm{~S}$ stores, and $\mu_{\mathrm{r}}$ stands for the effect of the recycling effort of the $4 \mathrm{~S}$ stores on recycling quantities, which also is known as the recycling effort effect coefficient. Previous relevant literature [24] found that the recycling 
effort cost of $4 \mathrm{~S}$ stores was $e_{\mathrm{r}}^{2}$. Therefore, the profit function of manufacturers, $4 \mathrm{~S}$ stores, and recycling networks is

$$
\pi_{\mathrm{m}}^{\mathrm{R}}\left(\omega, p_{\mathrm{m}}\right)=\left(\omega-C_{\mathrm{m}}\right) q+\left(C_{\mathrm{m}}-C_{\mathrm{r}}\right)\left(q_{\mathrm{n}}^{R}+q_{\mathrm{r}}^{R}\right)-p_{\mathrm{m}}\left(q_{\mathrm{n}}^{R}+q_{\mathrm{r}}^{R}\right),
$$

Theorem 4. The optimal solutions of model $R$ are as follows:

$$
\begin{aligned}
\pi_{\mathrm{r}}^{\mathrm{R}}\left(p_{\mathrm{r}}, p, s_{\mathrm{r}}, e_{\mathrm{r}}\right)=(p-\omega) q+\left(p_{\mathrm{m}}-p_{\mathrm{r}}\right) q_{\mathrm{r}}^{R}+e_{\mathrm{r}} s_{\mathrm{r}}-e_{\mathrm{r}}^{2}-v_{\mathrm{r}}^{2}, \\
p_{\mathrm{m}}^{R *}=\frac{S-2 b_{1}\left(C_{\mathrm{m}}-C_{\mathrm{r}}\right)+2 b_{2}\left(C_{\mathrm{m}}-C_{\mathrm{r}}\right)-2 k g_{\mathrm{m}}}{4\left(b_{2}-b_{1}\right)}, \\
\omega^{R *}=\frac{\alpha+\beta C_{\mathrm{m}}}{2 \beta}, \\
p^{R *}=\frac{3 \alpha+\beta C_{\mathrm{m}}}{4 \beta}, \\
p_{\mathrm{n}}^{R *}=\frac{4 b_{1}^{3} \Delta+b_{1} b_{2}\left(7 S-2 b_{2} \Delta-12 \mu e_{\mathrm{r}}+2 k g_{\mathrm{m}}+12 A\right)+4 b_{2}^{2}\left(\mu e_{\mathrm{r}}+k g_{\mathrm{m}}-A\right)+2 b_{1}^{2}\left(-5 S-b_{2} \Delta+4 \mu e_{\mathrm{r}}-6 k g_{\mathrm{m}}-4 A\right)}{4\left(b_{1}-b_{2}\right)\left(4 b_{1}^{2}-b_{2}^{2}\right)} \\
p_{\mathrm{r}}^{R *}=\frac{4 b_{1}^{3} \Delta+4 b_{2}^{2}\left(S-\mu e_{\mathrm{r}}+k g_{\mathrm{m}}+A\right)-2 b_{1}^{2}\left(S+b_{2} \Delta+4 \mu e_{\mathrm{r}}+6 k g_{\mathrm{m}}-4 A\right)+b_{1} b_{2}\left(-5 S-2 b_{2} \Delta+12 \mu e_{\mathrm{r}}+2 k g_{\mathrm{m}}-12 A\right)}{4\left(b_{1}-b_{2}\right)\left(4 b_{1}^{2}-b_{2}^{2}\right)}, \\
s_{\mathrm{r}}^{R *}=\frac{S \mu_{\mathrm{r}} b_{1}-2 S \theta \mu_{\mathrm{r}} b_{1}+2 \mu_{\mathrm{r}} \rho b_{1}\left(v_{\mathrm{n}}-v_{\mathrm{r}}\right)}{-\left(2 b_{1}+b_{2}\right)^{2}}, \\
e_{\mathrm{r}}^{R *}=\frac{\mu_{\mathrm{r}} b_{2}\left(S-2 S \theta+2 \rho v_{\mathrm{n}}-2 \rho v_{\mathrm{r}}\right)}{2\left(\mu_{\mathrm{r}}^{2}-4 b_{1}-2 b_{2}\right)\left(2 b_{1}+b_{2}\right)} .
\end{aligned}
$$

Plugging the above optimal solution into the corresponding profit function, the optimal profit of manufacturers, $4 \mathrm{~S}$ stores, and recycling networks under the model $\mathrm{R}$ is $\pi_{\mathrm{m}}^{R *}, \pi_{\mathrm{r}}^{R *}$ and $\pi_{\mathrm{n}}^{R *}$.

Proposition 5. As $k$ increases, $p_{m}^{R *}$ increases accordingly.

Proposition 5 shows that, as consumers' awareness of green recycling increases, manufacturers' recycling prices of used power batteries increases. This indicates that increasing consumers' awareness of green recycling promotes the recycling quantity of power batteries, which influences the entire supply chain and the social environment in a positive way.

Proposition 6. As $e_{r}^{R *}$ increases, $p_{r}^{R *}$ decreases and $p_{n}^{R *}$ increases.

Proposition 6 shows that, under the model R, due to the $4 \mathrm{~S}$ stores' publicity and advertising, a certain cost of recycling effort is generated, and the quantity of recycling increases. Accordingly, the recycling price decreases, and recycling networks, in order to compete with $4 \mathrm{~S}$ stores for more customers, tend to increase its own recycling price to incentivize consumers to recycle used power batteries.

4.5. Recycling Network Subsidy Strategy (Model N). On March 2, 2018, seven ministries and commissions, including the Ministry of Industry and Information Technology of China, jointly issued the Implementation Plan for the Pilot Implementation of New Energy Vehicle Power Battery Recycling, which stipulated that the Beijing-Tianjin-Hebei, Yangtze River Delta, and Central Regions will be selected to launch new projects. The pilot work on the recycling and utilization of energy batteries for energy vehicles will currently focus on the pilot area but will expand to surrounding areas in the future. This paper combines policy requirements and realistic backgrounds, uses $e_{\mathrm{n}}$ to indicate the degree of recycling efforts of recycling networks, and uses $\mu_{\mathrm{n}}$ to indicate the influence of the recovery effort on recycling quantity, which is also known as the recycling effort effect coefficient. $e_{\mathrm{n}}^{2}$ is the cost of recycling effort of networks. Therefore, the recycling quantity of recycling networks and $4 S$ stores is $q_{\mathrm{n}}^{\mathrm{N}}=(1-\theta) S-b_{2} p_{\mathrm{r}}+b_{1} p_{\mathrm{n}}+\rho\left(v_{\mathrm{n}}-\right.$ $\left.v_{\mathrm{r}}\right)+k g_{\mathrm{m}}+\mu_{\mathrm{n}} e_{\mathrm{n}} \quad$ and $\quad q_{\mathrm{r}}^{\mathrm{N}}=\theta S-b_{2} p_{\mathrm{n}}+b_{1} p_{\mathrm{r}}+$ $\rho\left(v_{\mathrm{r}}-v_{\mathrm{n}}\right)+k g_{\mathrm{m}}-\mu_{\mathrm{n}} e_{\mathrm{n}}$. Therefore, the profit functions of manufacturers, $4 \mathrm{~S}$ stores, and recycling networks are

$$
\begin{aligned}
\pi_{\mathrm{m}}^{\mathrm{N}}\left(\omega, p_{\mathrm{m}}\right)= & \left(\omega-C_{\mathrm{m}}\right) q+\left(C_{\mathrm{m}}-C_{\mathrm{r}}\right)\left(q_{\mathrm{n}}^{\mathrm{N}}+q_{\mathrm{r}}^{\mathrm{N}}\right) \\
& -p_{\mathrm{m}}\left(q_{\mathrm{n}}^{\mathrm{N}}+q_{\mathrm{r}}^{\mathrm{N}}\right), \\
\pi_{\mathrm{r}}^{\mathrm{N}}\left(p_{\mathrm{r}}, p\right)= & (p-\omega) q+\left(p_{\mathrm{m}}-p_{\mathrm{r}}\right) q_{\mathrm{r}}^{\mathrm{N}}-v_{\mathrm{r}}^{2}, \\
\pi_{\mathrm{n}}^{\mathrm{N}}\left(p_{\mathrm{n}}, s_{\mathrm{n}}, e_{\mathrm{n}}\right)= & \left(p_{\mathrm{m}}-p_{\mathrm{n}}\right) q_{\mathrm{n}}^{\mathrm{N}}+e_{\mathrm{n}} s_{\mathrm{n}}-e_{\mathrm{n}}^{2}-v_{\mathrm{n}}^{2} .
\end{aligned}
$$


Theorem 5. The optimal solutions of model $N$ are as follows:

$$
\begin{aligned}
& \omega^{N *}=\frac{\alpha+\beta C_{\mathrm{m}}}{2 \beta}, \\
& p^{R *}=\frac{3 \alpha+\beta C_{\mathrm{m}}}{4 \beta}, \\
& p_{\mathrm{m}}^{N *}=\frac{S-2 b_{1}\left(C_{\mathrm{m}}-C_{\mathrm{r}}\right)+2 b_{2}\left(C_{\mathrm{m}}-C_{\mathrm{r}}\right)-2 k g_{\mathrm{m}}}{4\left(b_{2}-b_{1}\right)}, \\
& e_{\mathrm{n}}^{N *}=\frac{\left(b_{2}-b_{1}\right)\left(2 b_{1}+b_{2}\right) \mu_{\mathrm{n}}}{2\left(2 b_{1}-b_{2}\right)\left(4 b_{1}+2 b_{2}+\mu_{\mathrm{n}}^{2}\right)}, \\
& s_{\mathrm{n}}^{N *}=\frac{\left(-4 b_{1}^{2} \Delta+2 b_{1}\left(4 C+S+\Delta b_{2}-2 k g_{\mathrm{m}}\right)+b_{2}\left(-4 C-3 S+2 b_{2} \Delta-2 k g_{\mathrm{m}}\right)\right) \mu_{\mathrm{n}}}{16 b_{1}^{2}-4 b_{2}^{2}}, \\
& p_{\mathrm{r}}^{N *}=\frac{4 b_{1}^{3} \Delta+2 b_{1}^{2}\left(-5 S-b_{2} \Delta-6 k g_{\mathrm{m}}-4\left(C+e_{\mathrm{n}} \mu_{\mathrm{n}}\right)\right)}{4\left(b_{1}-b_{2}\right)\left(4 b_{1}^{2}-b_{2}^{2}\right)}+\frac{4 b_{2}^{2}\left(k g_{\mathrm{m}}-A-e_{\mathrm{n}} \mu_{\mathrm{n}}\right)+b_{1} b_{2}\left(7 S-2 b_{2} \Delta+2 k g_{\mathrm{m}}+12\left(A+e_{\mathrm{n}} \mu_{\mathrm{n}}\right)\right)}{4\left(b_{1}-b_{2}\right)\left(4 b_{1}^{2}-b_{2}^{2}\right)} \\
& p_{\mathrm{n}}^{N *}=\frac{4 b_{1}^{3} \Delta+b_{1} b_{2}\left(-5 S-2 b_{2} \Delta+2 k g_{\mathrm{m}}-12\left(A+e_{\mathrm{n}} \mu_{\mathrm{n}}\right)\right)}{4\left(b_{1}-b_{2}\right)\left(4 b_{1}^{2}-b_{2}^{2}\right)}+\frac{2 b_{1}^{2}\left(-S-b_{2} \Delta-6 k g_{\mathrm{m}}+4\left(A+e_{\mathrm{n}} \mu_{\mathrm{n}}\right)\right)+4 b_{2}^{2}\left(S+k g_{\mathrm{m}}+A+e_{\mathrm{n}} \mu_{\mathrm{n}}\right)}{4\left(b_{1}-b_{2}\right)\left(4 b_{1}^{2}-b_{2}^{2}\right)} .
\end{aligned}
$$

By substituting the above optimal solution into the corresponding main body profit function, the optimal profits of manufacturers, $4 \mathrm{~S}$ stores, and recycling networks under the model $\mathrm{N}$ are $\pi_{\mathrm{m}}^{N *}, \pi_{\mathrm{r}}^{N *}$, and $\pi_{\mathrm{n}}^{N *}$.

Proposition 7. As $g_{m}$ rises, $p_{m}^{N *}$ increases.

Proposition 7 shows that, as the greenness level of remanufactured power batteries increases, the greenness of the entire power battery CLSC increases. The greenness level of the recycling power batteries will thus be relatively high, so, in the reverse supply chain, manufacturers increase recycling prices.

\section{Numerical Simulation}

The former sections show the research and comparative analysis of the theoretical model for the dual-channel CLSC under different models, the equilibrium solutions in different situations, and several management enlightenments. Since some of the analytic solutions above are complicated, the conclusions are verified visually through numerical examples in this section. First, by comparing the five decision models in Section 4, the effectiveness analysis is performed on optimal recycling prices and profits. The sensitivity analysis is then used to study the influence of consumers' green recycling awareness $k$ on recycling prices. The influence of the greenness of power battery $g_{\mathrm{m}}$ on the recycling prices is also analyzed and so is the impact of recycling efforts $e_{\mathrm{r}}$ and $e_{\mathrm{n}}$ and the level of service $s_{\mathrm{r}}$ and $s_{\mathrm{n}}$ on the pricing of $4 \mathrm{~S}$ stores and recycling networks. In addition, we studied the literature related to this research [25] and combined it with the current status of the development of new energy vehicles in China in order to better analyze and elaborate upon management implications. By combining theoretical research with the practical conditions, we assume $C_{\mathrm{m}}=10, C_{\mathrm{r}}=5, \alpha=100, \beta=2, \rho=1, v_{\mathrm{n}}=3, v_{\mathrm{r}}=6, k=$ $0.5, S=200, \theta=0.6$, and $b_{1}, b_{2} \in[0,1]$.

5.1. Comparative Analysis of Optimal Prices under Different Strategies. From Table 2, the following conclusions can be obtained: (1) in the two models without government subsidies, the optimal recycling prices $p_{\mathrm{r}}$ and $p_{\mathrm{n}}$ under a decentralized model are smaller than the corresponding optimal recycling prices under a centralized model. This is because, under decentralized decision-making, each entity pursues the maximization of its own profits, which leads to the loss of profit in CLSC. (2) In all strategies, the sales price of remanufactured power batteries does not change, and in all decentralized models, the wholesale price of remanufactured power batteries also does not change, which indicates that the government's subsidies provided to the entities in the recycling link have nothing to do with the prices in the sales link. (3) In all decentralized models, $p_{\mathrm{r}}, p_{\mathrm{n}}$, and $p_{\mathrm{m}}$ are relatively high in model $M$, benefiting all members of the supply chain and stimulating the prosperity of the new energy vehicle industry. This is because the subsidies provided by the manufacturers have an incentive effect on the recycling of the downstream enterprises. The increase in the greenness level of power batteries is conducive to promoting the recycling of used power batteries, which increases the recycling quantity that $4 \mathrm{~S}$ stores and recycling networks obtained. When the 
TABle 2: Comparison of optimal prices under different strategies.

\begin{tabular}{lccccc}
\hline Optimal price & Model ND & Model NC & Model M & Model R & Model N \\
\hline$p_{\mathrm{r}}$ & 184.30 & 260.91 & 195.08 & 228.53 \\
$p_{\mathrm{n}}$ & 197.59 & 249.09 & 205.48 & 217.47 & 218.37 \\
$p_{\mathrm{m}}$ & 291.76 & 1 & 302.01 & 260.61 & 260.61 \\
$\omega$ & 30 & 1 & 30 & 30 & 30 \\
$p$ & 40 & 40 & 40 & 40 & 40 \\
\hline
\end{tabular}

government increases subsidies, manufacturers can make higher profits; thus, more money is spent on the dismantling and remanufacturing of power batteries, promoting the long-term development of the new energy industry.

\subsection{Sensitivity Analysis}

5.2.1. Consumer Green Recycling Awareness $k$ and Power Battery Greenness Level $g_{m}$. It can be seen from Figure 2 that, as consumers' awareness of green recycling $k$ increases, $p_{\mathrm{r}}, p_{\mathrm{n}}$, and $p_{\mathrm{m}}$ increase. Take the optimal solutions of the model D. From the perspective of consumers, the rising recycling awareness of consumers means that they prefer to buy green batteries. Since there is more dismantling and remanufacturing value in the recycling process of green batteries, $4 \mathrm{~S}$ stores and recycling networks will offer higher recycling prices than for batteries that are not green. Therefore, when the consumers' awareness of recycling is improving, the greater the proportion of green batteries among power batteries in the CLSC, the higher the recycling prices. In addition, from the perspective of the manufacturers, according to the increase in recycling prices $p_{\mathrm{r}}, p_{\mathrm{n}}$, and $p_{\mathrm{m}}$ due to the selected set of greenness levels $g_{\mathrm{m}} \in\{3,5,7\}$, when consumers have the same awareness of recycling, the greater the proportion of green batteries among power batteries, the higher the corresponding recycling prices. In summary, from the manufacturers' perspective, manufacturers should proactively improve the greenness of power batteries, increase environmental consciousness, and promote the recycling of power batteries in the recycling process. From the consumers' perspective, increasing the awareness of green recycling is not only more economical and environmentally friendly for consumers who use new energy vehicles but also conducive to promoting the sales of new energy vehicles with high green levels. As a result, economic efficiency and environmental indicators will both increase in the entire CLSC.

5.2.2. Recycling Effort $e_{n}$ and $e_{r}$. From Figure 3, as the $4 S$ stores' recycling effort $e_{\mathrm{r}}$ increases, the recycling price $p_{\mathrm{r}}$ decreases, while that of its competitive channel recycling networks increase. This is because the more the $4 \mathrm{~S}$ stores' recycling effort, the higher the cost of its recycling effort. At the same time, the improvement of the recycling effort of $4 \mathrm{~S}$ stores directly increases the recycling quantity; thus, the recycling prices of them decrease accordingly. On the contrary, the recycling networks compete with $4 \mathrm{~S}$ stores for customers and will increase their recycling prices to incentivize consumers to recycle used power batteries there. Correspondingly, the impact of the recycling effort $e_{\mathrm{n}}$ of the recycling networks on the recycling prices work in the same way. Since the financial resources of recycling companies are always limited, the financial status of different recycling companies is often quite different. Although when enterprises have high levels of recycling efforts, there will be higher government subsidies. However, the cost of recycling efforts will also rise. Recycling companies are advised to balance the relationship between the level of recycling efforts and the quantity of subsidies. While ensuring a certain level of effort, they must also consider the rising costs due to the increase in the quantity of recycling.

5.2.3. Service Level $v_{r}$ and $v_{n}$. As can be seen from Figures 4(a) and 4(b), when a service level rises, this party's recycling price decreases accordingly because a higher service level increases the party's service cost. However, the other party, since they have a relatively low service level and are at a competitive disadvantage, intends to increase their recycling price to improve some competitiveness in order to incentivize consumers to recycle used power batteries there. Thus, the recycling price of one party is inversely related to the service level of the other party.

From Figures 4(c) and 4(d), when the service level of one party increases, the profit of that party first increases and then decreases. For $4 S$ stores and recycling networks in the CLSC, when the service level increases from 0 to a certain level, their profits have a positive correlation with the service level. This is because the improvement in service level attracts more consumers; thus, the recycling quantity of this party increases, and the increase in revenue due to the increase in recycling quantity is greater than the cost caused by the increase in service level. However, when the service level increases to a certain level, and the party's profit reaches its 


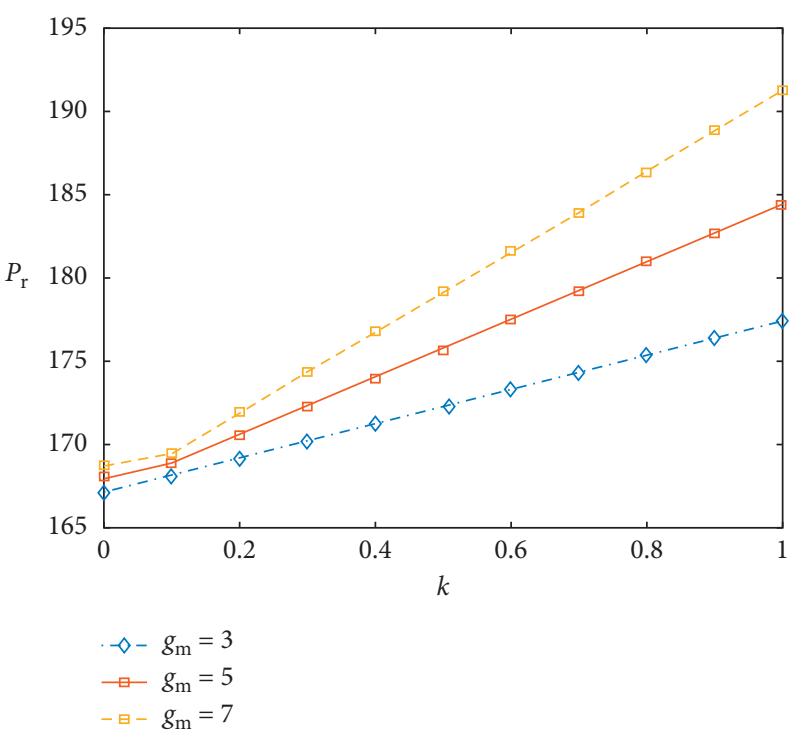

(a)

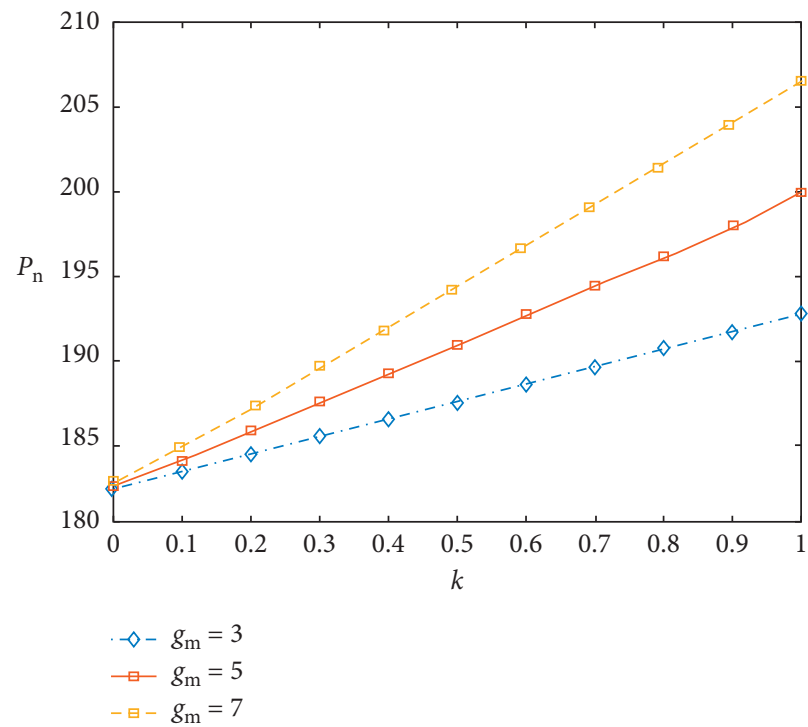

(b)

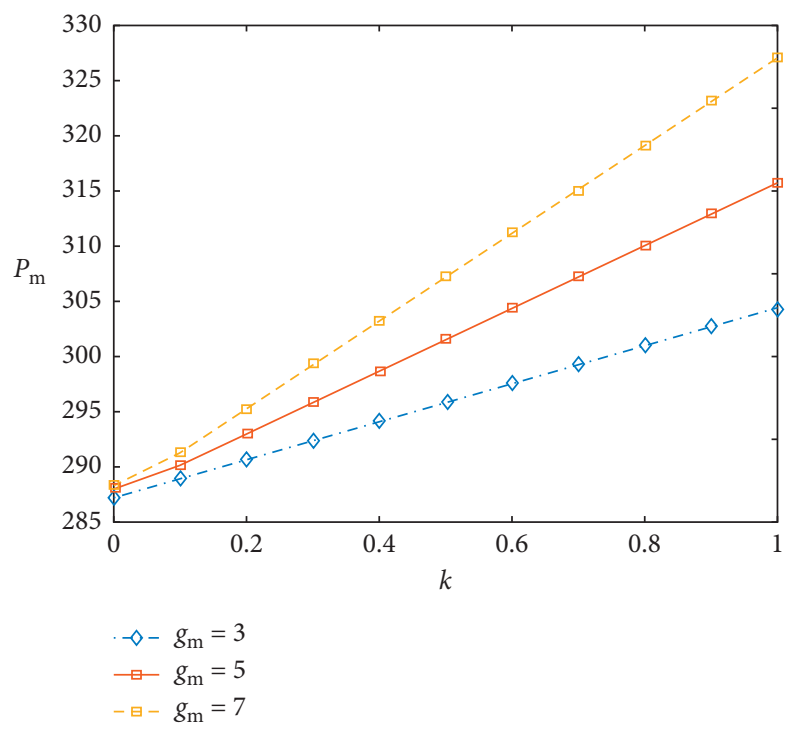

(c)

FIGURE 2: Impact of consumers' green recycling consciousness $k$ and power battery greenness $g_{\mathrm{m}}$ on recycling prices $p_{\mathrm{r}}, p_{\mathrm{n}}$, and $p_{\mathrm{m}}$ : (a) the influence of consumers' green recycling consciousness $k$ on recycling price $p_{r}$; (b) the influence of consumers' green recycling consciousness $k$ on recycling price $p_{\mathrm{n}}$; (c) the influence of consumers' green recycling consciousness $k$ on recycling price $p_{\mathrm{m}}$.

maximum, the profits of recycling parties will show a downward trend. At this time, the cost will be greater than the increase in revenue caused by a rise in demand. This brings us certain management inspiration: in the process of power battery recycling, enterprises should maintain an appropriate service level in the light of the industry environment and their own actual conditions and take into account the cost due to the rising service level. It is inadvisable to only maintain the service level promotion blindly and neglect the balance between service level and the service level cost. 


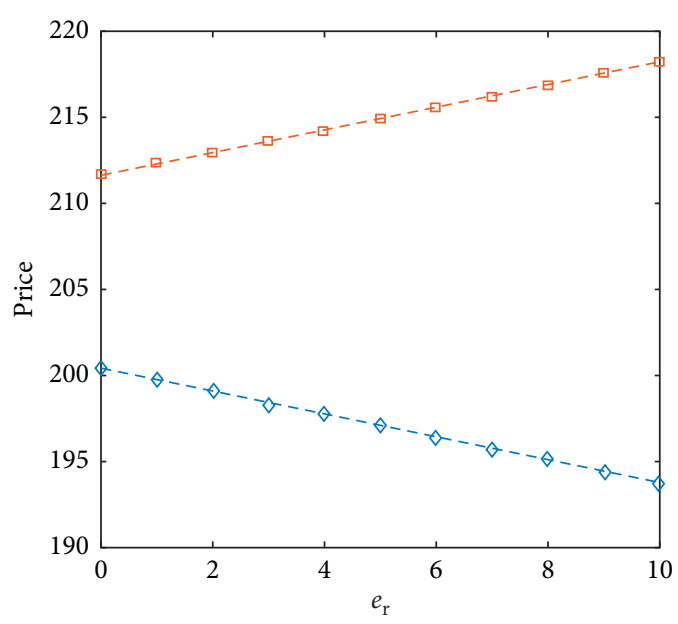

$$
\begin{aligned}
& -\diamond-p_{\mathrm{r}} \\
& - \text { - } p_{\mathrm{n}}
\end{aligned}
$$

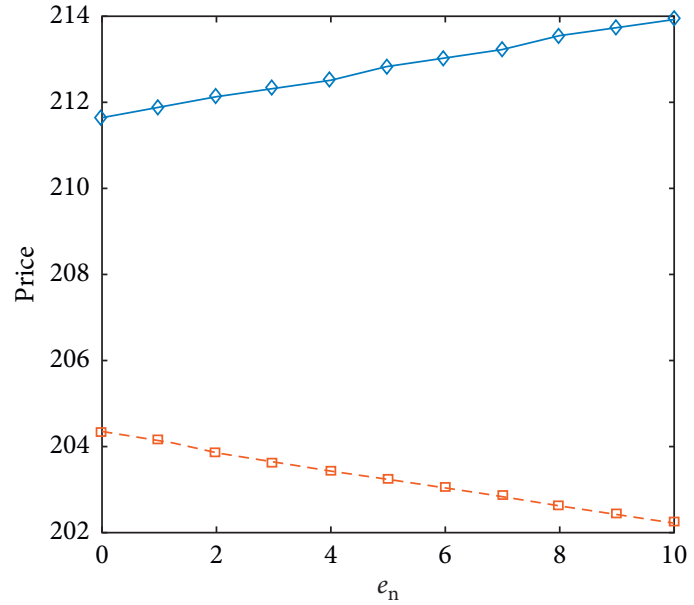

$\neg p_{\mathrm{r}}$

-日- $p_{\mathrm{n}}$

(a)

(b)

Figure 3: Impact of recycling effort $e_{\mathrm{n}}$ and $e_{\mathrm{r}}$ on recycling prices $p_{\mathrm{r}}$ and $p_{\mathrm{n}}$ : (a) the influence of recycling effort $e_{\mathrm{r}}$ on recycling prices $p_{\mathrm{r}}$ and $p_{\mathrm{n}}$; (b) the influence of recycling effort $e_{\mathrm{n}}$ on recycling prices $p_{\mathrm{r}}$ and $p_{\mathrm{n}}$.

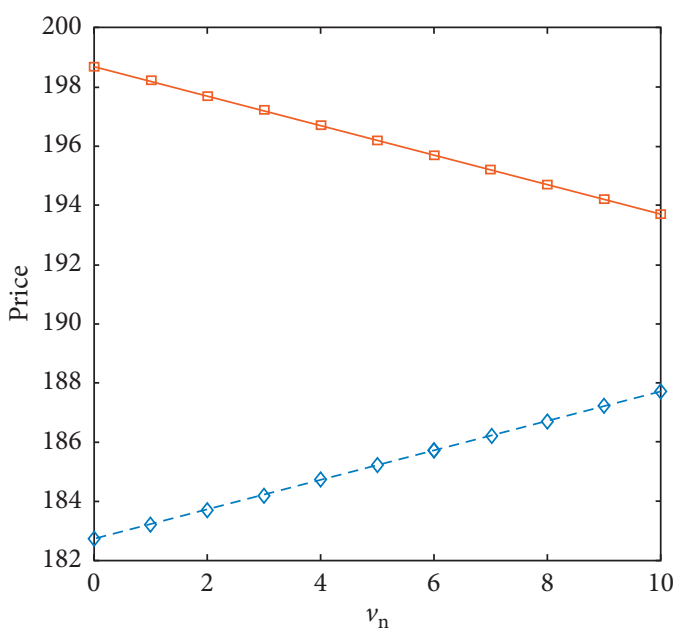

$-\diamond-p_{\mathrm{r}}$

$\rightarrow-p_{\mathrm{n}}$

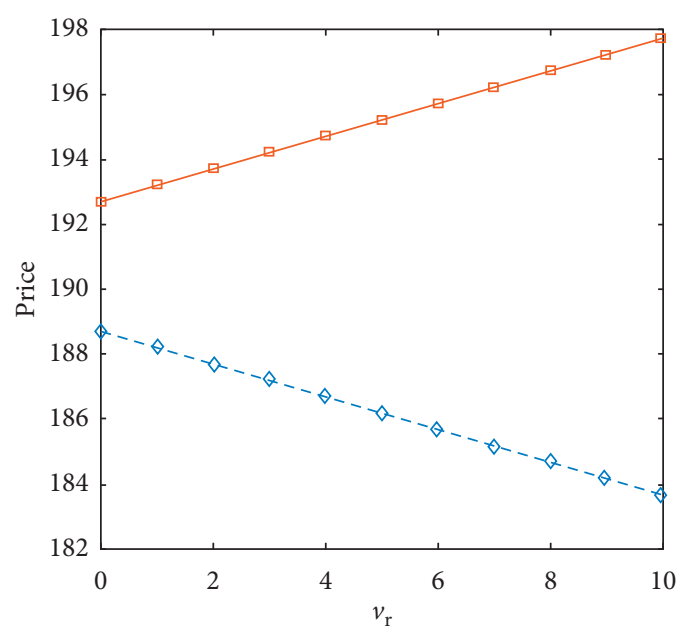

$-\diamond-p_{\mathrm{r}}$

$\because-p_{\mathrm{n}}$

(b)

Figure 4: Continued. 


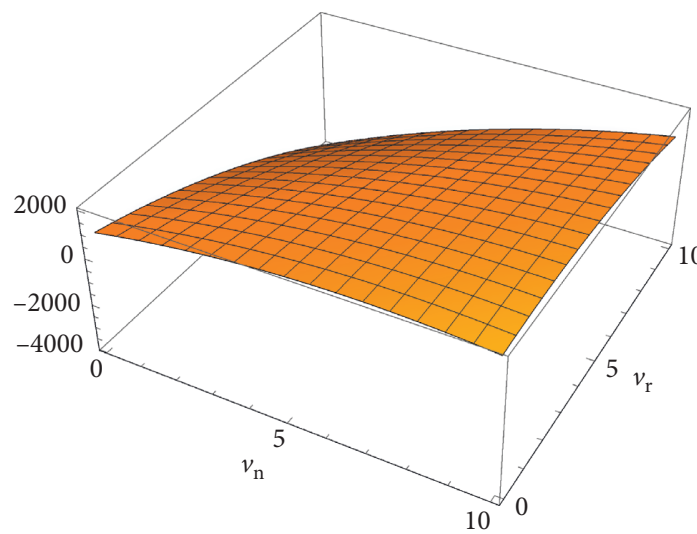

$\pi_{n}^{*}$

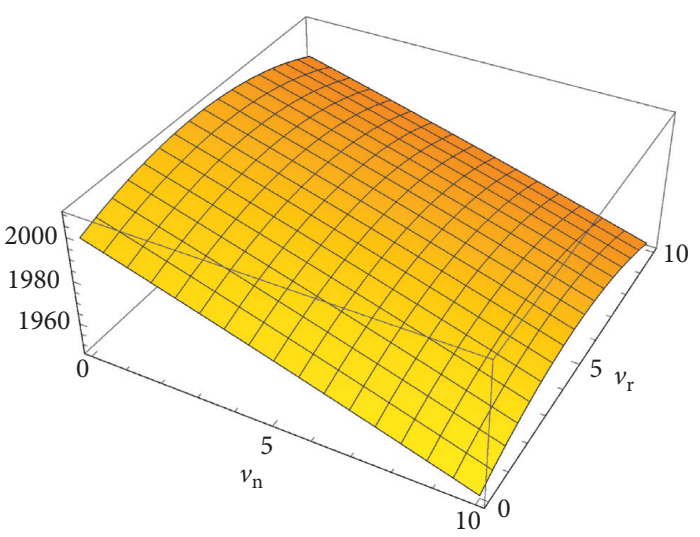

$\pi_{r}^{*}$

(c)

(d)

FIGURE 4: Impact of service level $v_{\mathrm{n}}$ and $v_{\mathrm{r}}$ on pricing and profit of recycling networks and automobile $4 \mathrm{~S}$ stores: (a) the influence of recycling effort $v_{\mathrm{n}}$ on recycling prices $p_{\mathrm{r}}$ and $p_{\mathrm{n}}$; (b) the influence of recycling effort $v_{\mathrm{r}}$ on recycling prices $p_{\mathrm{r}}$ and $p_{\mathrm{n}}$; (c) the influence of recycling efforts $v_{\mathrm{n}}$ and $v_{\mathrm{r}}$ on the profit of automobile $4 \mathrm{~S}$ stores; (d) the influence of recycling efforts $v_{\mathrm{n}}$ and $v_{\mathrm{r}}$ on the profit of recycling networks.

\section{Conclusion}

This paper studies the price structure and profit situation of the recycling of waste power batteries in a CLSC without government subsidies and with subsidies for each party. By introducing the recycling effort, product green levels, service levels, and consumer green awareness, the optimal price structure of each party under different models is solved, the influences of each factor on the recycling prices of power battery are analyzed, and the optimal prices under different strategies are compared. The conclusions are as follows:

(1) In the five dual-channel models, when the government subsidizes the manufacturers, the recycling price of each main party of the supply chain is relatively high. Firstly, since the manufacturer is the first mover in the Stackelberg model game and $4 \mathrm{~S}$ stores and recycling networks are followers, manufacturers often enjoy the first mover advantage. When there are preferential subsidy policies provided by the government, the first mover advantage is relatively obvious. Secondly, from the perspective of the recycling link of the supply chain, when subsidies are given to manufacturers, the recycling prices given by manufacturers to $4 \mathrm{~S}$ stores and recycling networks will increase significantly compared with other subsidy policies. In this way, the recycling prices given to consumers by $4 S$ stores and recycling networks will also increase to a certain extent. The manufacturer-subsidy strategy greatly promotes the recycling of waste power batteries by consumers. Consumers are thus willing to recycle, which increases the recycling number of waste power batteries. Thirdly, from the perspective of the sales link of the supply chain, although the government does not subsidize the sales link, due to the large number of recycled waste power batteries and the fast turnover of the supply chain, the stock of remanufactured power batteries is sufficient, and the development of the new energy automobile industry is promoted.

(2) The recycling price of each recycling party in the supply chain has positive correlations with the green recycling awareness of consumers and the green level of power batteries. When consumers are more aware of green recycling, they are more inclined to buy new energy vehicles with high green levels and actively recycle waste power batteries. Therefore, in the recycling process, waste power batteries with high green levels account for a relatively high proportion and are more valuable for disassembly and remanufacturing. Thus, the recycling prices given by $4 \mathrm{~S}$ stores, recycling networks, and manufacturers can increase. This brings certain management enlightenments to recycling enterprises: we should encourage consumers to recycle power batteries, popularize the economic and environmental benefits of green products, and strive to enhance consumers' awareness of green recycling. For manufacturers, it is necessary to improve their green level in the process of power battery remanufacturing to promote the overall benefits of the CLSC.

(3) Recycling enterprises should pay attention to balance the cost due to recycling efforts and the quantity of government subsidies and then make appropriate recycling efforts according to their economic actual situation. With improvements in recycling efforts, government subsidies given to $4 \mathrm{~S}$ stores or recycling networks will increase, however, at the same time, so will the cost of recycling efforts. At this time, enterprises need to choose their own operation strategies according to their own financial situation and development space. It is advised to maintain 
recycling efforts and government subsidies while ensuring appropriate recycling prices.

(4) Service level is an important factor to be considered for recycling enterprises. Maintaining an appropriate service level has a positive impact on the development of enterprises. Too high or too low service levels will damage the profits of enterprises. When the service level is improved, there will be two impacts: an increase in service level cost and an increase in recycling quantity. When the increase in revenue due to the increase in recycling quantity is greater than the increase in cost due to the service level, an increase in the service level results in increased profits for the enterprise. On the contrary, when the increase in revenue due to the increase in recycling quantity is smaller than the increase in cost due to the service level, an increase in service level results in decreased profits for enterprises. Consequently, in the process of recycling power batteries, enterprises should maintain an appropriate service level in combination with the industry environment and their own actual situation and take into account the cost due to the rise of service level. It is not advised to just maintain the improvement of service level and subsequently ignore the balance between service level and service level costs.

(5) The main management implications of this paper are as follows: first, for manufacturers who enjoy a firstmover advantage in the supply chain, government subsidies provided to them can greatly stimulate the quantity of power battery recycling and have a greater positive incentive effect on the remanufacturing industry chain. In the case of limited government subsidies, subsidies to manufacturers is a better choice. Second, it is urgent for recycling enterprises and environmental management departments to build a complete recycling network system together. In combination with the local economic development level, battery production and recycling, and other specific conditions, policies conducted to encourage consumers' recycling should be adjusted and refined. Measures such as repurchase and trade-in can be adopted to improve the enthusiasm of users to hand over waste power batteries. From the aspect of product quality, manufacturers should improve the greenness level of power batteries in order to innovate consumers to recycle. Third, in terms of the service level and recycling efforts of recycling enterprises, enterprises should maintain certain recycling efforts and service levels to improve their competitive advantages. However, excessive improvement will aggravate the competition, and vicious service competition will cause damage to the benefits of enterprises and the supply chain, which is not conducive to the long-term development of recycling enterprises. Additionally, enterprises should consider the cost caused by the increase in recycling efforts and service level and weigh the input of both according to their own economic level, recycling, and operation capacity.

\section{Appendix}

\section{A. Theorems}

Proof of Theorem 1. The backward induction was used to solve the model. First, the first-order partial derivative of $\pi_{\mathrm{r}}^{\mathrm{ND}}$ with respect to $p$ and $p_{\mathrm{r}}$ and the first-order partial derivative of $\pi_{\mathrm{n}}^{\mathrm{ND}}$ with respect to $p_{\mathrm{n}}$ are obtained; their equations can be obtained by setting their partial derivatives equal to 0 in parallel: $p^{\mathrm{ND}}=(\alpha+\beta \omega) / 2 \beta, p_{\mathrm{r}}^{\mathrm{ND}}=(-S \theta-$ $\left.k g_{\mathrm{m}}+b_{1} p_{\mathrm{m}}+b_{2} p_{\mathrm{n}}+\rho v_{\mathrm{n}}-\rho v_{\mathrm{r}}\right) / 2 b_{1}$, and $p_{\mathrm{n}}^{\mathrm{ND}}=(-S+S \theta-$ $\left.k g_{\mathrm{m}}+b_{1} p_{\mathrm{m}}+b_{2} p_{\mathrm{r}}-\rho v_{\mathrm{n}}+\rho v_{\mathrm{r}}\right) / 2 b_{1}$. According to equation (2), the Hessian matrices can be easily solved as follows:

$$
H\left(p_{\mathrm{r}}, p\right)=\left(\begin{array}{c}
-2 \beta \\
0 \\
0 \\
-2 b_{1}
\end{array}\right) \text {. }
$$

According to the assumptions, $\beta>0$ and $b_{1}>0$. Thus, the Hessian matrix of $\pi_{\mathrm{r}}^{\mathrm{ND}}$ is negative, which means that $\pi_{\mathrm{r}}^{\mathrm{ND}}$ is a strictly concave function concerning $p_{\mathrm{r}}$ and $p \cdot p_{\mathrm{n}}$ is the only variable in equation (3). Consequently, the optimal equilibrium solutions of the two equations are unique.

Plugging $p^{\mathrm{ND}}, p_{\mathrm{r}}^{\mathrm{ND}}$, and $p_{\mathrm{n}}^{\mathrm{ND}}$ into equation (1), the derivatives of $\pi_{\mathrm{m}}^{\mathrm{ND}}$ with respect to $\omega$ and $p_{\mathrm{m}}$ are, respectively, obtained. According to equation (1), the Hessian matrix can be easily solved:

$$
H\left(p_{\mathrm{m}}, \omega\right)=\left(\begin{array}{cc}
-\frac{\beta}{2} & 0 \\
0 & b_{2}-b_{1}
\end{array}\right)
$$

According to the assumptions, $\beta>0$ and $b_{1}>b_{2}$. Thus, the Hessian matrix of $\pi_{\mathrm{m}}^{\mathrm{ND}}$ is negative, which means that $\pi_{\mathrm{m}}^{\mathrm{ND}}$ is a strictly concave function concerning $\omega$ and $p_{m}$, and the optimal equilibrium solutions of the equation are unique. Then, the optimal solutions $p_{\mathrm{m}}^{N D *}$ and $\omega^{N D *}$ can be solved.

By substituting $p_{\mathrm{m}}^{N D *}$ and $\omega^{*}$ into $p_{\mathrm{r}}^{\mathrm{ND}}, p^{\mathrm{ND}}$, and $p_{\mathrm{n}}^{\mathrm{ND}}$, the optimal solutions $p_{\mathrm{r}}^{N D *}, p^{N D *}$, and $p_{\mathrm{n}}^{N D *}$ can be obtained.

Proof of Theorem 2. First, the derivatives of $\pi^{\mathrm{NC}}$ with respect to $p, p_{\mathrm{r}}$, and $p_{\mathrm{n}}$ were, respectively, obtained.

According to equation (5), the Hessian matrix can be easily solved as follows:

$$
H\left(p, p_{\mathrm{r}}, p_{\mathrm{n}}\right)=\left(\begin{array}{ccc}
-2 \beta & 0 & 0 \\
0 & -2 b_{1} & 2 b_{2} \\
0 & 2 b_{2} & -2 b_{1}
\end{array}\right) \text {. }
$$

According to the assumptions, $\beta>0$ and $b_{1}>b_{2}>0$. Then, $H_{1}<0, H_{2}>0$, and $H_{3}<0$. Thus, the Hessian matrices of $\pi^{\mathrm{NC}}$ is negative, which means that $\pi^{\mathrm{NC}}$ is a strictly concave 
function concerning $p, p_{r}$, and $p_{n}$. Then, the unique optimal solutions can be solved.

Proof of Theorem 3. The method used is consistent with the above models. First, derive $\pi_{\mathrm{r}}^{\mathrm{M}}$ with respect to $p$ and $p_{\mathrm{r}}$ and derive $\pi_{\mathrm{n}}^{\mathrm{M}}$ with respect to $p_{\mathrm{n}}$; then, make all equations equal to 0 . The equations can be solved: $p^{\mathrm{M}}=(\alpha+\beta \omega) / 2 \beta, p_{\mathrm{r}}^{\mathrm{M}}=$ $\left(-S \theta-k g_{\mathrm{m}}+b_{1} p_{\mathrm{m}}+b_{2} p_{\mathrm{n}}+\rho v_{\mathrm{n}}-\rho v_{\mathrm{r}}\right) / 2 b_{1}$ $p_{\mathrm{n}}^{\mathrm{M}}=\left(-S+S \theta-k g_{\mathrm{m}}+b_{1} p_{\mathrm{m}}+b_{2} p_{\mathrm{r}}-\rho v_{\mathrm{n}}+\rho v_{\mathrm{r}}\right) / 2 b_{1}$ :

$$
H\left(\omega, p_{\mathrm{m}}, t\right)=\left(\begin{array}{ccc}
-\beta & 0 & 0 \\
-\beta & 0 & 0 \\
0 & \frac{4\left(b_{2}-b_{1}\right)}{2 b_{1}-b_{2}} & \frac{C_{\mathrm{r}}\left(g_{\mathrm{m}}-g\right)\left(2 b_{1}^{3}-b_{1}\right)}{b_{1}\left(2 b_{1}-b_{2}\right)}
\end{array}\right) .
$$

According to the assumptions, $\beta>0, b_{1}>b_{2}>$ $0, C_{\mathrm{r}}>0$, and $g_{\mathrm{m}}>g$. Then, $H_{1}<0, H_{2}>0$, and $H_{3}<0$. The Hessian matrices of equations (7)-(9) remain negative, and optimal solutions of model $M$ are unique. Plugging $p^{\mathrm{M}}, p_{\mathrm{r}}^{\mathrm{M}}$, and $p_{\mathrm{n}}^{\mathrm{M}}$ into equation (7), the derivatives of $\pi_{\mathrm{m}}^{\mathrm{M}}$ with respect to $\omega, p_{\mathrm{m}}$, and $t$ are, respectively, obtained. Then, the optimal solutions $p_{\mathrm{m}}^{M *}, \omega^{M *}$, and $t_{\mathrm{m}}^{M *}$ can be solved. By substituting $p_{\mathrm{m}}^{M *}$ and $\omega^{M *}$ into $p, p_{\mathrm{r}}$, and $p_{\mathrm{n}}$, the optimal solutions $p^{M *}, p_{\mathrm{n}}^{M *}$, and $p_{\mathrm{r}}^{M *}$ can be solved as well.

Proof of Theorem 4. The backward induction was used to solve the model. First, the first-order partial derivative of $\pi_{\mathrm{r}}^{\mathrm{R}}$ with respect to $p$ and $p_{\mathrm{r}}$ and the first-order partial derivative of $\pi_{\mathrm{n}}^{\mathrm{R}}$ with respect to $p_{\mathrm{n}}$ are obtained, and their equations can be obtained by setting the partial derivatives equal to 0 in parallel:

$$
H\left(p, p_{\mathrm{r}}, s_{\mathrm{r}}, e_{\mathrm{r}}\right)=\left(\begin{array}{cccc}
-2 \beta & 0 & 0 & 0 \\
0 & -2 b_{1} & -\mu_{\mathrm{r}} & 0 \\
0 & -\mu_{\mathrm{r}} & -2 & 1 \\
0 & 0 & 1 & 0
\end{array}\right) .
$$

According to the assumptions, $\beta>0$ and $b_{1}>b_{2}>0$. Then, $H_{1}<0, H_{2}>0, H_{3}<0$, and $H_{4}>0$. Similar to the previous section, the optimal solutions of equations (11)-(13) are unique since the Hessian matrices are negative. Then, the following solutions can be solved: $p^{\mathrm{R}}=(\alpha+\beta \omega) / 2 \beta, \quad p_{\mathrm{r}}^{\mathrm{R}}=\left(-S \theta-\mu e_{\mathrm{r}}-k g_{\mathrm{m}}+b_{1} p_{\mathrm{m}}+\right.$ $\left.b_{2} p_{\mathrm{n}}+\rho v_{\mathrm{n}}-\rho v_{\mathrm{r}}\right) / 2 b_{1}$, and $p_{\mathrm{n}}^{\mathrm{R}}=\left(-S+S \theta+\mu e_{\mathrm{r}}-k g_{\mathrm{m}}+\right.$ $\left.b_{1} p_{\mathrm{m}}+b_{2} p_{\mathrm{r}}-\rho v_{\mathrm{n}}+\rho v_{\mathrm{r}}\right) / 2 b_{1}$.

Substituting $p^{\mathrm{R}}, p_{\mathrm{r}}^{\mathrm{R}}$, and $p_{\mathrm{n}}^{\mathrm{R}}$ into equation (11), the derivatives of $\pi_{\mathrm{m}}^{\mathrm{R}}$ concerning $\omega$ and $p_{\mathrm{m}}$ are, respectively, obtained. Then, the optimal solutions $p_{\mathrm{m}}^{R *}$ and $\omega^{R *}$ can be solved. By substituting $p_{\mathrm{m}}^{R *}$ and $\omega^{R *}$ into $p, p_{\mathrm{r}}$, and $p_{\mathrm{n}}$, the optimal solutions $p^{R *}, p_{\mathrm{n}}^{R *}$, and $p_{\mathrm{r}}^{R *}$ can be solved as well. Finally, we took the derivatives of $\pi_{\mathrm{r}}^{\mathrm{R}}$ concerning $s_{\mathrm{r}}$ and $e_{\mathrm{r}}$, respectively. The optimal solutions of model $R$ can be solved.

Proof of Theorem 5. The first-order partial derivative of $\pi_{\mathrm{r}}^{\mathrm{N}}$ with respect to $p$ and $p_{\mathrm{r}}$ and the first-order partial derivative of $\pi_{\mathrm{n}}^{\mathrm{N}}$ with respect to $p_{\mathrm{n}}$ are obtained, and then, their equations can be obtained by setting the partial derivatives equal to 0 in parallel:

$$
H\left(\omega, p_{\mathrm{m}}, t\right)=\left(\begin{array}{ccc}
\frac{2 b_{2}^{2}-4 b_{1}^{2}}{2 b_{1}} & \frac{\mu_{\mathrm{n}}\left(b_{2}-2 b_{1}\right)}{2 b_{1}} & 0 \\
\mu_{\mathrm{n}}\left(\frac{b_{2}}{2 b_{1}}-1\right) & -2 & 1 \\
0 & 1 & 0
\end{array}\right) .
$$

According to the assumptions, $\quad \beta>0, b_{1}>b_{2}>$ $0, C_{\mathrm{r}}>0$, and $g_{\mathrm{m}}>g$. Then, $H_{1}<0, H_{2}>0$, and $H_{3}<0$. The Hessian matrices of equations (15)-(17) are negative, and the optimal solutions of them are unique. Then, the optimal solutions of the simultaneous equations are $p^{\mathrm{N}}=(\alpha+\beta \omega) / 2 \beta, \quad p_{\mathrm{n}}^{\mathrm{N}}=\left(-S+S \theta-k g_{\mathrm{m}}+b_{1} p_{\mathrm{m}}+b_{2} p_{\mathrm{r}}-\right.$ $\left.\rho v_{\mathrm{n}}+\rho v_{\mathrm{r}}-e_{\mathrm{n}} \mu_{\mathrm{n}}\right) / 2 b_{1}$, and $p_{\mathrm{r}}^{\mathrm{N}}=\left(-S \theta-k g_{\mathrm{m}}+b_{1} p_{\mathrm{m}}+\right.$ $\left.b_{2} p_{\mathrm{n}}+\rho v_{\mathrm{n}}-\rho v_{\mathrm{r}}+e_{\mathrm{n}} \mu_{\mathrm{n}}\right) / 2 b_{1}$.

Plugging $p^{\mathrm{N}}, p_{\mathrm{r}}^{\mathrm{N}}$, and $p_{\mathrm{n}}^{\mathrm{N}}$ into equation (15), the derivatives of $\pi_{\mathrm{m}}^{\mathrm{N}}$ with respect to $\omega$ and $p_{\mathrm{m}}$ are, respectively, obtained. Then, the optimal solutions $p_{\mathrm{m}}^{N *}$ and $\omega^{N *}$ can be solved. By substituting $p_{\mathrm{m}}^{N *}$ and $\omega^{N *}$ into $p, p_{\mathrm{r}}$, and $p_{\mathrm{n}}$, the optimal solutions $p^{N *}, p_{\mathrm{n}}^{N *}$, and $p_{\mathrm{r}}^{N *}$ can be solved as well. Finally, plugging $p^{N *}, p_{\mathrm{r}}^{N *}$, and $p_{\mathrm{n}}^{N *}$ into equation (17), we took the derivatives of $\pi_{\mathrm{n}}^{\mathrm{N}}$ concerning $s_{\mathrm{n}}$ and $e_{\mathrm{n}}$, respectively. The optimal solutions of model $\mathrm{N}$ can be solved.

\section{B. Propositions}

Proof of Proposition 1. $\partial q_{\mathrm{r}} / \partial b_{1}=p_{\mathrm{r}}>0, \partial q_{\mathrm{n}} / \partial b_{1}=p_{\mathrm{n}}>0$, and it can be evidently found that $q_{\mathrm{r}}$ and $q_{\mathrm{n}}$ are increasing functions concerning $b_{1}$.

Proof of Proposition 2. $\partial p_{\mathrm{r}} / \partial k=\left(4 b_{1}^{3} g_{\mathrm{m}}+10 b_{1}^{2} b_{2} g_{\mathrm{m}}+\right.$ $\left.2 b_{1} b_{2}^{2} g_{\mathrm{m}}+2 b_{2}^{3} g_{\mathrm{m}}\right) /\left(4 b_{1}\left(b_{1}-b_{2}\right)\left(4 b_{1}^{2}-b_{2}^{2}\right)\right)$, and $\partial p_{\mathrm{n}} / \partial k=$ $\left(2 b_{1} b_{2}^{2} g_{\mathrm{m}}+2 b_{2}^{3} g_{\mathrm{m}}+4 b_{1}^{3} g_{\mathrm{m}}+10 b_{1}^{2} b_{2} g_{\mathrm{m}}\right) /\left(4 b_{1}\left(b_{1}-b_{2}\right)\left(4 b_{1}^{2}-\right.\right.$ $\left.\left.b_{2}^{2}\right)\right)$. It can be evidently found that $\partial p_{\mathrm{r}} / \partial k, \partial p_{\mathrm{n}} / \partial k>0$. Proposition 2 is proved.

Proof of Proposition 3. According to assumptions, $b_{1}>b_{2}$, $\partial p_{\mathrm{r}} /\left(\partial\left(v_{\mathrm{n}}-v_{\mathrm{r}}\right)\right)=\partial p_{\mathrm{n}} /\left(\partial\left(v_{\mathrm{n}}-v_{\mathrm{r}}\right)\right)=\left(8 \rho b_{1}^{3}-12 \rho b_{1}^{2} b_{2}+4\right.$ $\left.\rho b_{1} b_{2}^{2}\right) /\left(4 b_{1}\left(b_{1}-b_{2}\right)\left(4 b_{1}^{2}-b_{2}^{2}\right)\right)=\rho /\left(2 b_{1}+b_{2}\right)>0 . \quad \partial p_{\mathrm{n}} /(\partial$ $\left.\left(v_{\mathrm{n}}-v_{\mathrm{r}}\right)\right)=\left(-\rho b_{1}+\rho b_{2}\right) /\left(2\left(b_{1}^{2}-b_{2}^{2}\right)\right)<0$. Proposition 3 is proved.

Proof of Proposition 4. $\partial t / \partial g_{\mathrm{m}}=\left(-(2 g k+S) b_{1} b_{2}+(2 g k+\right.$ $\left.S) b_{2}^{2}-b_{1}^{2}\left(-2 g k+S+2 b_{2}\left(C_{\mathrm{m}}-C_{\mathrm{r}}\right)\right)+2 b_{1}^{3}\left(C_{\mathrm{m}}-C_{\mathrm{r}}\right)\right) /$ $\left(2 b_{1}^{2}\left(b_{1}-b_{2}\right) C_{\mathrm{r}}\left(g-g_{\mathrm{m}}\right)^{2}\right)=\left((2 g k+S)\left(b_{2}^{2}+b_{1}^{2}-b_{1} b_{2}\right)+\right.$ $\left.\left(2 b_{1}^{3}-2 b_{1}^{2} b_{2}\right)\left(C_{\mathrm{m}}-C_{\mathrm{r}}\right)\right) /\left(2 b_{1}^{2}\left(b_{1}-b_{2}\right) C_{\mathrm{r}}\left(g-g_{\mathrm{m}}\right)^{2}\right)$. Since $b_{1}>b_{2}$ and $b_{2}^{2}+b_{1}^{2}-b_{1} b_{2}>0, \partial t / \partial g_{\mathrm{m}}>0$. According to the government unit subsidy coefficient $r=t\left(g_{\mathrm{m}}-g\right), r$ will also increase as $g_{\mathrm{m}}$ and $t$ both rise.

Proof of Proposition 5. Since $\partial p_{\mathrm{m}}^{R *} / \partial k=k g_{\mathrm{m}} /$ $\left(2\left(b_{1}-b_{2}\right)\right)>0$, Proposition 5 is proved. 
Proof of Proposition 6. According to assumptions, $b_{1}>b_{2}$, then $\partial p_{\mathrm{r}}^{R *} / \partial e_{\mathrm{r}}=\left(4 \mu b_{2}^{2}-8 \mu b_{1}^{2}+12 \mu b_{1} b_{2}\right) /\left(4\left(b_{1}-b_{2}\right)\left(4 b_{1}^{2}-\right.\right.$ $\left.\left.b_{2}^{2}\right)\right)<0$ and $\partial p_{\mathrm{n}}^{R *} / \partial e_{\mathrm{r}}=\left(4 \mu b_{2}^{2}+8 \mu b_{1}^{2}+12 \mu b_{1} b_{2}\right) /\left(4\left(b_{1}-\right.\right.$ $\left.\left.b_{2}\right)\left(4 b_{1}^{2}-b_{2}^{2}\right)\right)>0$.

Proof of Proposition 7. $b_{1}>b_{2}>0$; thus, $\partial p_{\mathrm{m}}^{N *} / \partial g_{\mathrm{m}}=k /$ $\left(2\left(b_{1}-b_{2}\right)\right)>0$. Proposition 7 is proved.

\section{Data Availability}

The data used to support the findings of this study are included within the article.

\section{Conflicts of Interest}

The authors declare that they have no conflicts of interest.

\section{Acknowledgments}

This paper received administrative and technical support from the China Institute of Manufacturing Development. This research was funded by the Ministry of China of Education of Humanities and Social Science Project (Grant no. 19YJC630240) and the Practice Innovation Training Program of College Students in Jiangsu Province (Grant no. 201910300045Z).

\section{References}

[1] Y. A. Alamerew and D. Brissaud, "Modelling reverse supply chain through system dynamics for realizing the transition towards the circular economy: a case study on electric vehicle batteries," Journal of Cleaner Production, vol. 254, Article ID 120025, 2020.

[2] M. Zhu, Z. Liu, J. Li, and S. X. Zhu, "Electric vehicle battery capacity allocation and recycling with downstream competition," European Journal of Operational Research, vol. 283, no. 1, pp. 365-379, 2020.

[3] J. Li, Y. Ku, C. Liu, and Y. Zhou, "Dual credit policy: promoting new energy vehicles with battery recycling in a competitive environment?" Journal of Cleaner Production, vol. 243, Article ID 118456, 2020.

[4] G. Harper, R. Sommerville, E. Kendrick et al., "Recycling lithium-ion batteries from electric vehicles," Nature, vol. 575, no. 7781, pp. 75-86, 2019.

[5] A. Betancourt-Torcat, T. Poddar, and A. Almansoori, "A realistic framework to a greener supply chain for electric vehicles," International Journal of Energy Research, vol. 43, no. 6, pp. 2369-2390, 2019.

[6] Y. Tang, Q. Zhang, Y. Li, H. Li, X. Pan, and B. Mclellan, "The social-economic-environmental impacts of recycling retired EV batteries under reward-penalty mechanism," Applied Energy, vol. 251, p. 113313, 2019.

[7] P. He, Y. He, and H. Xu, "Channel structure and pricing in a dual-channel closed-loop supply chain with government subsidy," International Journal of Production Economics, vol. 213, pp. 108-123, 2019.

[8] A. A. Taleizadeh, F. Haghighi, and S. T. A. Niaki, "Modeling and solving a sustainable closed loop supply chain problem with pricing decisions and discounts on returned products," Journal of Cleaner Production, vol. 207, pp. 163-181, 2019.

[9] M. O. Kabul and A. K. Parlaktürk, "The value of commitments when selling to strategic consumers: a supply chain perspective," Management Science, vol. 65, no. 10, pp. 4754-4770, 2019.
[10] C. M. Chen and H. Ho, "Who pays you to be green? How customers' environmental practices affect the sales benefits of suppliers' environmental practices," Journal of Operations Management, vol. 65, no. 4, pp. 333-352, 2019.

[11] P. Zhang and Z. Xiong, "Incentive contract design for retailers under asymmetric manufacturer recycling cost information," Journal of Industrial Engineering and Engineering Management, vol. 33, no. 4, pp. 144-150, 2019.

[12] Z. Pi, W. Fang, and B. Zhang, "Service and pricing strategies with competition and cooperation in a dual-channel supply chain with demand disruption," Computers \& Industrial Engineering, vol. 138, Article ID 106130, 2019.

[13] J. Xie, L. Liang, G. Yang, F. Kong, and Y. Chen, "Revenue sharing and cost sharing contract coordination and optimization of complementary closed-loop supply chain," China Journal of Management Science, vol. 26, no. 8, pp. 94-105, 2018.

[14] J. P. Xie, L. Liang, L. H. Liu, and P. Ieromonachou, "Coordination contracts of dual-channel with cooperation advertising in closed-loop supply chains," International Journal of Production Economics, vol. 183, pp. 528-538, 2017.

[15] C. Ma, T. Zhong, J. Wang, and J. He, "Risk diversification contract with retailer effort effect under loss avoidance," Journal of Industrial Engineering and Engineering Management, vol. 1-9, 2019.

[16] Z. Wang, J. Huo, and Y. Duan, "Impact of government subsidies on pricing strategies in reverse supply chains of waste electrical and electronic equipment," Waste Management, vol. 95, pp. 440-449, 2019.

[17] S. Mitra and S. Webster, "Competition in remanufacturing and the effects of government subsidies," International Journal of Production Economics, vol. 111, no. 2, pp. 287-298, 2008.

[18] P. Calcott and M. Walls, "Waste, recycling, and "design for environment": roles for markets and policy instruments," Resource and Energy Economics, vol. 27, no. 4, pp. 287-305, 2005.

[19] P. E. Pfeifer and A. Ovchinnikov, "A note on willingness to spend and customer lifetime value for firms with limited capacity," Journal of Interactive Marketing, vol. 25, no. 3, pp. 178-189, 2011.

[20] J. Guo, L. He, and M. Gen, "Optimal strategies for the closedloop supply chain with the consideration of supply disruption and subsidy policy," Computers \& Industrial Engineering, vol. 128, pp. 886-893, 2019.

[21] J. Zhao and N. Sun, "Government subsidies-based profits distribution pattern analysis in closed-loop supply chain using game theory," Neural Computing and Applications, vol. 32, no. 6, pp. 1715-1724, 2020.

[22] N. Wan and D. Hong, "The impacts of subsidy policies and transfer pricing policies on the closed-loop supply chain with dual collection channels," Journal of Cleaner Production, vol. 224, pp. 881-891, 2019.

[23] I. E. Nielsen, S. Majumder, and S. Saha, "Game-theoretic analysis to examine how government subsidy policies affect a closed-loop supply chain decision," Applied Sciences, vol. 10, no. 1, p. 145, 2019.

[24] X. Lu, J.-S. Song, and A. Regan, "Rebate, returns and price protection policies in channel coordination," IIE Transactions, vol. 39, no. 2, pp. 111-124, 2007.

[25] A. Atasu, M. Sarvary, and L. N. Van Wassenhove, "Remanufacturing as a marketing strategy," Management Science, vol. 54, no. 10, pp. 1731-1746, 2008. 